Florida International University FIU Digital Commons

$11-2-2011$

\title{
Middle School Teachers' Intentions to Refer Eating Disorder Students for Professional Counseling
}

Diann P. Carr

diannc@bellsouth.net

DOI: $10.25148 /$ etd.FI11120710

Follow this and additional works at: https://digitalcommons.fiu.edu/etd

\section{Recommended Citation}

Carr, Diann P., "Middle School Teachers' Intentions to Refer Eating Disorder Students for Professional Counseling" (2011). FIU Electronic Theses and Dissertations. 517.

https://digitalcommons.fiu.edu/etd/517 


\section{FLORIDA INTERNATIONAL UNIVERSITY \\ Miami, Florida}

\section{MIDDLE SCHOOL TEACHERS' INTENTIONS TO REFER EATING DISORDER STUDENTS FOR PROFESSIONAL COUNSELING}

A dissertation submitted in partial fulfillment of the requirements for the degree of DOCTOR OF EDUCATION

in

HIGHER EDUCATION

by

Diann Carr

2011 
To: Dean Delia C. Garcia

College of Education

This dissertation, written by Diann Carr, and entitled Middle School Teachers' Intentions to Refer Eating Disorder Students for Professional Counseling, having been approved in respect to style and intellectual content, is referred to you for judgment.

We have read this dissertation and recommend that it be approved.

Charmaine DeFrancesco

Janice Sandiford

JoAnn Kleier

Joan Wynne, Major Professor

Date of Defense: November 2, 2011

The dissertation of Diann Carr is approved

Dean Delia C. Garcia

College of Education

Dean Lakshmi N. Reddi

University Graduate School

Florida International University, 2011 
CCopyright 2011 by Diann Carr

All rights reserved. 


\section{DEDICATION}

This dissertation is dedicated with my deepest love and affection to my husband, Murray. His encouragement and support inspired me to fulfill my dream of completing my advanced degree in the field of education. 


\section{ACKNOWLEDGMENTS}

First and foremost, I want to thank God for providing me with the strength and fortitude so I could complete this dissertation. Special thanks to my husband, Murray, for his continued support and understanding. He helped me fulfill my dream to complete this advanced degree. I would also like to thank my three children along with their spouses for their encouragement and continued support.

I will always be grateful for the support and guidance from my major professor, Dr. J. Wynne. Her positive attitude, enthusiasm, expertise, and caring manner helped throughout this journey. In addition, I would like to express thanks to all the members of my dissertation committee, Dr. C. DeFrancesco, Dr. J. Sandiford, Dr. J. Kleier, for their guidance and suggestions. Thank you to my former committee member, Dr. M. Farouk, for his support and encouragement during this journey.

Furthermore, I would like to thank all the participants in this study. Regrettably, I cannot acknowledge them by name. I deeply appreciate their willingness to volunteer in the study.

Lastly, thanks to Jorge, the illustrator, for his permission to include his illustration on the flyer I used in this study. 


\title{
ABSTRACT OF THE DISSERTATION \\ MIDDLE SCHOOL TEACHERS' INTENTIONS TO REFER EATING DISORDER STUDENTS FOR PROFESSIONAL COUNSELING
}

\author{
by \\ Diann Carr \\ Florida International University, 2011 \\ Miami, Florida \\ Professor Joan Wynne, Major Professor
}

Eating disorders can lead to a negative impact on students' academic growth, nutrition and can cause death (Claude-Pierre, 1997; Manley, Rickson, \& Standeven, 2000; Romeo, 1996). Early intervention by referring students to professional counseling might help counter these negative consequences. The teacher is in the position to assist students by providing health information, identifying those with problems, and intervening for a variety of dysfunctions that may include the eating disorders called anorexia nervosa and bulimia nervosa (Myers-Clark \& Christopher, 2000). However teachers are in a difficult position to know when to address student concerns and judge what action to take (Ransley,1999). Teachers' engagement seems crucial (Smolak, Harris, Levine, \& Shisslak, 2001) since eating disorders are being identified in younger children.

The purpose of this study was to examine (a) the relationships of the theoretical constructs, attitude, subjective norm, and perceived behavioral control of the theory of planned behavior as predictors of behavioral intention (Ajzen \& Fishbein, 1980) of middle school teachers to identify and refer suspected anorexia nervosa (AN) and/or bulimia nervosa $(\mathrm{BN})$ students for professional help; and (b) the actual behavior of 
middle school teachers who reported having ever referred a student suspected of having $\mathrm{AN}$ and $\mathrm{BN}$ and those teachers who reported not having made such a referral.

One hundred fourteen middle school teachers in Broward County, Florida volunteered to participate in the ex post facto research. Data were collected from a questionnaire. Multiple regression analysis revealed that the constructs of subjective norm (perception of what others think about one's performance of behavior combined with motivation to comply) and perceived behavioral control (perception regarding the extent of the difficulty of performing the behavior) were predictive of teachers' intent (likelihood of engaging in a behavior) to refer. However, the analysis revealed that attitude (overall positive or negative feeling with respect to performing the behavior) was not predictive of teachers' intent. Discriminant function analysis revealed that both intent and perceived behavioral control were predictive of group membership, either having referred a student suspected of having an eating disorder for counseling or not having made such a referral. Attitude and subjective norm were not predictive of group membership. 


\section{TABLE OF CONTENTS}

CHAPTER

PAGE

I. INTRODUCTION .....................................................

Background of the Problem............................................. 2

Statement of the Problem............................................ 5

Purpose of the Study................................................. 5

Research Questions............................................. 6

Significance of the Study.......................................... 6

Theoretical Framework........................................... 10

Delimitations of the Study............................................ 17

Definitions of Terms.............................................. 18

Assumptions........................................................ 20

Summary ....................................................... 21

Overview of Chapters............................................... 21

II. REVIEW OF LITERATURE..................................................... 22

Review of Related Literature........................................... 22

Discussion......................................................... 37

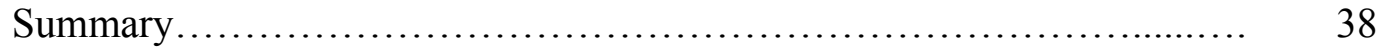

Overview of Chapters............................................. 40

III. METHOD ................................................................... 41

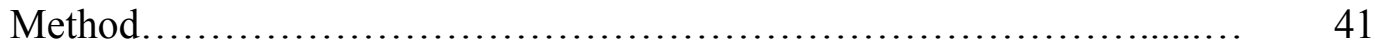

Research Design................................................. 41

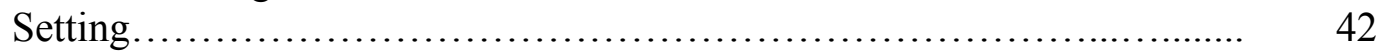

Sample......................................................... 43

Protection of Human Subjects........................................ 43

Instrumentation....................................................... 45

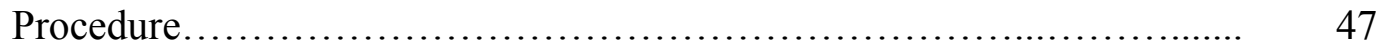

Statistical Analysis Plan............................................ 49

Hypothesis Testing.................................................. 52

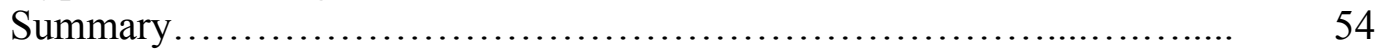

Overview of Chapter................................................. 55

IV. RESULTS ........................................................................ 56

Descriptives.......................................................... 57

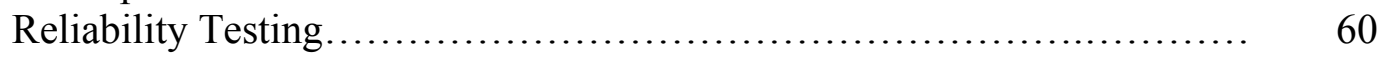

Hypothesis Testing............................................ 60

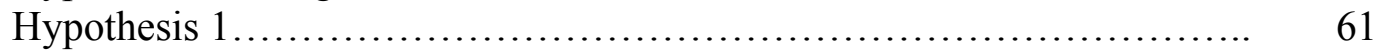

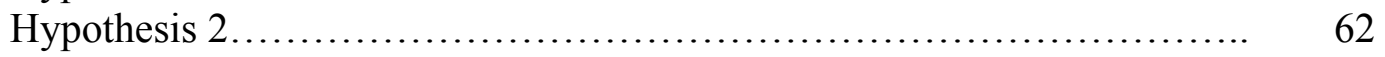

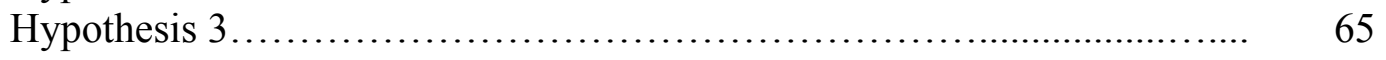

Qualitative Information........................................... 66

Summary ............................................................. $\quad 70$

Overview of Chapter................................................ 71 


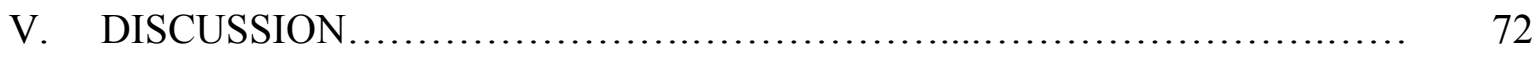

Results........................................................... 73

Limitations of the Study.......................................... 76

Implications for the Study.................................... 78

Recommendations for Future Research........................... 82

Conclusions................................................ 83

LIST OF REFERENCES ............................................. 85

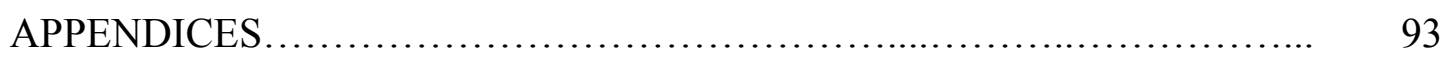

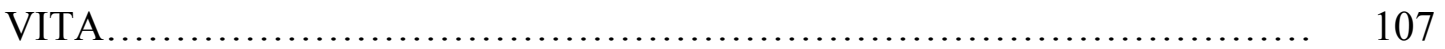




\section{LIST OF TABLES}

TABLE. PAGE

1. Demographic Characteristics of Participants................................. 59

2. Descriptive Statistics for the Scores of the Research Variables ................... 60

3. Intercorrelations for the Outcome Criterion of Intent and Constructs ................ 63

4. Predictor Variables as a Function of the Outcome Variable .............................. 65

5. Classification Analysis for Group Membership............................................. 65

6. Regression Analysis Summary for Variables Predicting Behavioral Intent......... 66 


\section{CHAPTER I \\ INTRODUCTION}

Teachers are significant figures in the lives of school-aged children and can be influential in the process of health promotion and illness prevention while facilitating learning (Wisenhunt, 2002). They are perfectly positioned and have great potential to help with these efforts in all grade levels of education (Yager \& O’Dea, 2005). One particularly significant time to intercede is preadolescence since this is a period where young people become more "at-risk" for physical, psychological, behavioral and academic problems (Barnes, Courtney, Pratt, Walsh, \& Prom, 2004; Calabrese, Hummel, \& San Martin, 2007; Shahid, 2003; Wisenhunt, 2002).

The teacher, willing or not, is in the front position to assist students by providing health information, identifying those with problems and intervening with students for a variety of physical, emotional, and social ills that include among others, the eating disorders (ED) called anorexia nervosa and bulimia nervosa (Myers-Clark \& Christopher, 2000). Research studies suggest that teachers can play a meaningful role for students dealing with EDs (Barnes et al., 2004) even before symptoms become evident (Kates, Rohwer, \& Londre, 2002; Smolak et al., 2001; St. Leger \& Nutbeam, 2000;

Wisenhunt, 2002). Yet, limited scientific inquiry has examined the theoretical antecedents of teachers' behavior toward implementation of preventive measures or their actual behavior in this regard (Paxton, 1999; Piran, 2004b; Wisenhunt, 2002; Yager \& O’Dea, 2005). 


\section{Background of the Problem}

Eating disorders are a great mystery of our time, an enigma to the medical and psychological professionals as well as those who live with these disorders (Claude-Pierre, 1997; Hellings \& Bowles, 2007; laGrange \& Loeb, 2007). Two forbidding and dangerous eating disturbances are anorexia nervosa $(\mathrm{AN})$ and bulimia nervosa $(\mathrm{BN})$. These give rise to a vast source of apprehension and trepidation causing major nutritional, psychological, physiological, social and academic problems (Manley et al., 2000; Videbeck, 2008). All too often, these disorders are misunderstood, remain unfixed, imprison individuals, and affect them negatively (Natenshon, 1996; Webb, 1994).

\section{The Changing Face of Eating Disorders}

Anorexia nervosa and bulimia nervosa have long been recognized as problems in the United States (Becker, Grinspoon, Klibanski, \& Herzog, 2002; Dixon-Works, 2003; Levitt, 2001; McEwen, 2003; Phelps, Sapia, Natanshon, \& Nelson, 2000). They have been referred to as a "silent epidemic" affecting all ages and ethnic groups starting in early to mid-adolescence to adulthood (Claude-Pierre, 1997; Kohn \& Golden, 2001), with females reported as the largest number of persons affected. Over 7 million women and 1 million men in the United States (US) have some form of an eating disorder (Murray, 2003; Nathenshon, 1996). It is likely that the number of 1 million men is underestimated, is not an anomaly and should not be minimized but considered a real problem (Crosscope-Happel, 1999). According to McEwen (2003), many times females are affected with EDs; however, males may account for 5 to $10 \%$ of the cases. 
According to Hoek and van Hoeken (2003), AN and BN are relatively common among adolescent girls as well as young women. There are at least eight AN cases per 100,000 population per year, and at least 12 cases per 100,000 population per year of BN reported. Typically EDs become evident as the individual enters the turbulent high school years (Manley et al., 2000; Pryor \& Widerman, 1998). However, they are more noticeable and prevalent as early as preadolescence, affecting children in middle and elementary schools (Black, 2002; Sands, Tricker, Sherman, \& Armatas, 1998).

Most research on body dissatisfaction has focused on females (McCabe \& Ricciardell, 2004). However, preadolescents, especially girls, but also boys, as young as 6 and 8 years old are demonstrating a preoccupation with body image, body dissatisfaction, and dieting (Black, 2002; Manley et al., 2000). Skemp-Arit, Rees, Mikat and Seebach (2006) also found that body image dissatisfaction has become increasingly more prevalent with preadolescents, females and males, in recent years. The overall results of their study indicated that $50.6 \%$ of 216 third, fourth and fifth graders surveyed were not satisfied with their body shape. Of the $50.6 \%$, the findings showed that $50 \%$ of the girls were not satisfied with their body shape with $45.1 \%$ wanting to be thinner. Similar trends regarding dissatisfaction with body shape was evidenced in boys. Of the boys, $48.9 \%$ were dissatisfied with their body shape and $38.9 \%$ wanted to be thinner. According to McCabe and Ricciardelli (2004), male children have a strong similarity with body dissatisfaction as do female children. This fixation and preoccupation has been identified as the presage of eating disorders (Black, 2002; Manley et al., 2000; Wiederman \& Pryor, 2000) and prevention strategies, along with education, should be implemented for both genders as early as elementary grades (Skemp-Arit, Rees, Mikat \& Seebach, 2006). 


\section{The Changing Responsibilities for Teachers}

Teachers' responsibilities have become more complex with the expectation that they take a more active role in identifying students with physical or mental problems and in referring them to proper authorities (Bureau of Labor Statistics, 2009; Dee, 2002; Napoli, 2004;Wisenhunt, 2002). Traditionally these issues, including eating disorders, were primarily handled by the school counselors, school psychologists, school nurses or administration. However, today the classroom teachers are being recruited to handle these types of issues and expected to refer students for counseling (Barnes et al., 2004).

According to Rees and Clark-Stone (2006), classroom teachers are more aware of pupils with $\mathrm{AN}$ and $\mathrm{BN}$, even more so than the school nurse. Therefore, expecting teachers to intervene seems to be fitting. However, there is evidence and concern that teachers are apt to carry out prevention activities with little professional support and knowledge (Yager \& O’Dea, 2005). In order for teachers to intervene, there needs to be specialized training in AN and BN. According to Chally (1998), the majority of Florida's teachers were not receiving any special training to identify students with eating disorders. Basic educational preparation for elementary school teachers only provided three semester hours in general health, often combined with physical education; educational preparation for secondary school teachers provided no health training (Chally, 1998).

Despite their increased responsibility in other areas, teachers have expressed a desire to acquire the necessary education and skills to intervene with students demonstrating EDs (Layton 2003; Napoli, 2000; Natenshon, 1996; Neumark-Sztainer, Story, \& Collier, 1999; Piran, 2004a; Smolak et al., 2001). Without eating disorder education and support for referrals, teachers may feel ill equipped, helpless, stressed and 
frustrated to give assistance and make referrals for students (Hellings \& Bowles, 2007). Piran (2004a) and the research of Yager and O'Dea (2005) acknowledge that there is much to be learned regarding anorexia nervosa and bulimia nervosa and that a better understanding of these disorders would benefit teachers and students alike.

\section{Statement of the Problem}

The teachers' role has changed from primarily focusing on cognitive development, more specifically, reading, writing and arithmetic. Their responsibilities have become more multifaceted (Dee, 2002; Napoli, 2003; Roeser \& Midgley, 1997) with the addition of understanding the student's emotional needs (Bureau of Labor Statistics, 2009). This situation places teachers in the difficult position of knowing when to address student concerns and judge what action to take (Ransley, 1999). According to Natenshon (1996), more education is needed for those working in schools.

In view of the fact that eating disorders are being identified in younger children and can negatively impact their academic growth, nutrition, and can cause death (ClaudePierre, 1997; Manley et al., 2000; Romeo, 1996) the teachers' engagement seems absolutely crucial (Smolak et al., 2001). Research studies have confirmed that teachers' beliefs, attitudes, motivation, and perceived availability of resources directly affect their behavior (O'Dea \& Abraham, 2001; Piran, 2004a). Therefore, understanding the relationship of these factors regarding interventions for suspected ED students in this study is paramount (Neumark-Sztainer, Story, \& Coller, 1999; Yager \& O’Dea, 2005).

\section{Purpose of the Study}

The purpose of this study was to examine (a) the relationships of the theoretical constructs of the theory of planned behavior (TPB): attitude, subjective norm, and 
perceived behavioral control as predictors of behavioral intention (Ajzen \& Fishbein, 1980) when middle school teachers identified and referred students suspected of AN and $\mathrm{BN}$ for professional help; and (b) the actual behavior of middle school teachers that reported having ever referred a student suspected of having AN and BN and those teachers that reported not having made such a referral.

\section{Research Questions}

The research questions that direct this study were based on the theoretical foundation of Ajzen and Fishbein's theory of planned behavior (Peterson \& Bredow, 2004). The three questions are:

Question 1: Are there statistically significant relationships, uniquely and as a linear composite, between the theoretical constructs, attitude, subjective norms, and perceived behavioral control and the behavioral intent of middle school teachers to refer students suspected of AN and BN for professional counseling?

Question 2: Is there a statistically significant difference in the mean scores for behavioral intent between the middle school teachers that report having ever referred a student suspected of having AN and BN and those middle school teachers that report not having made such a referral?

Question 3: What is the proportion of unique variance that each of the three constructs, attitude, subjective norms, and behavioral control, contributes to predicting teacher intention to refer?

\section{Significance of the Study}

The significance of this study is threefold focusing on the aspects of middle school education, middle school practice and research. Identifying the motivational 
factors that influence teachers' intention to refer students suspected of AN and BN will help teachers understand the barriers that may be preventing early referral for professional counseling. These findings may enlighten administrations that there is a need for workshops, resources, support services and strategies to implement referrals when classroom teachers suspect students of AN and BN. Hopefully, teachers will be better able to identify and refer students for professional help to prevent the devastating effects on their physical, psychological and academic development.

From a middle school educational perspective, "children and adolescents suffering from ED will typically experience an adverse impact of such a disorder upon their education" (Hellings \& Bowles, 2007, p. 60) even though they appear to be an exemplary student. As AN and BN progress, the student's learning process, well being, mood, cognitive ability, and physical health are negatively affected. The starving practices of these disorders actually cause the brain to function differently, impacting the student's educational outcomes. The inadequate nutritional intake negatively impacts the student's cognitive ability, physical health, ability to concentrate and academic performance (Black, 2002; Hellings \& Bowles, 2007). Thus, early interventions by teachers could reach a wide range of students (Smolak et al., 2001) promoting a more positive physical and mental outcome.

Hellings and Bowles (2007) findings indicate that eating disorders cause serious concern and adverse impact on students' education. Given the stability of the school environment, raising awareness about ED and prevention measures among those that work with students, particularly teachers and administration, would be beneficial to the 
students (Ransley, 1999). Adequately prepared teachers could become "resource brokers" for the students dealing with mental health issues (Roeser \& Midgley, 1998).

From a teaching point of view, teachers have an unparalleled opportunity to reach a large group of students, which affords them an occasion to recognize the signs of eating disorders (Smolak et al., 2001). Since teachers are in this position of observing students on a daily basis, they could easily identify changes in the behavior of students, and refer them for help (Layton, 2003). This may be more likely to occur if teachers feel it is part of their responsibility, and if they have the skills to address the situation. In as much as teachers are asked to be involved in the area of illness prevention, it is conceivable that if they have the knowledge of the intrinsic and extrinsic factors affecting their participation with early referrals, perhaps ED students' educational and specialized needs can be met more quickly (Manley et al., 2000).

Earlier research has suggested that teachers want to know more about eating disorders so they are better prepared with skills to refer students for professional counseling (Smolak, et al., 2001). Therefore identifying and analyzing the motivational factors that affect the teachers' intentions to refer students for help would empower teachers, make referrals unrestrained, and give them confidence that they are personally and professionally capable of carrying out the measures to assist students (Yager \& O’Dea, 2005).

In the practice setting, teachers could be a valuable force to support and encourage students to seek expert guidance since few adolescents choose to seek professional psychological help for eating disorder problems on their own (Carlton \& Deane, 2000). Teachers have an opportunity on a daily basis to observe the physical, 
psychological, social, as well as educational impairments of children, therefore, offering a favorable avenue to alleviate the immense challenge students have coping with an eating disorder illness (Kate, Rohwer, \& Londre, 2002).

Although mental issues related to students are addressed primarily by the school counselor, psychologist, school nurse or administration, classroom teachers can have a greater impact because they have more time with the student. Clearly teachers should not act as a diagnostician, but they can act as the link between a suspected ED student, school resource person and the professional counselor (Layton, 2003).

Since teachers are faced with the daunting responsibility of monitoring physical, psychological, and social well being of their students, understanding the factors that influence their intention to refer suspected ED students should encourage them to become more active in enlisting help for the students. Recognizing the factors that underlie teachers' willingness to accept and act on referring students will provide insight into the teachers' intent to assume this additional responsibility.

The findings from this study should add to the previous empirical studies. Not only will the findings assist middle school teachers, school personnel, and administrators; they will help teachers in all levels of education. The results could guide administration to earmark support services, provide workshops focusing on eating disorders, endorse the idea of a school resource person, and establish school policy for guidance and referral process (Smolak et al., 2001).

The results of this study could also guide faculty in the field of teacher education to incorporate classes on eating disorders in their undergraduate and graduate curriculum. Last, the study will add to the limited research of the TPB by identifying the motivational 
factors affecting teachers' behavioral intent and actual behavior of making referrals for those students demonstrating signs of an ED.

\section{Theoretical Framework}

The TPB was used as the conceptual framework to examine middle school teachers' behavioral intention to refer suspected eating disordered students to a professional for counseling. The TPB was developed by Ajzen and Fishbein approximately two decades after they developed the theory of reasoned action (TRA) in 1967 (Peterson \& Bredow, 2004). The central factor of TPB focuses on an individual's intention to engage in a specific behavior. This theoretical model aided in predicting, explaining and understanding the intrapersonal motivating factors that influence middle school teachers' that are not under their volitional control (Ajzen, 1991; Housman, 2006; Peterson \& Bredow, 2004; Rhodes \& Courneya, 2003). The theory examined three conceptual independent antecedents of intention identified as attitude, subjective norm and perceived behavioral control, which in the final analysis ascertains an individual's intentions and actions (Ajzen, 1991) shown in Figure 1.

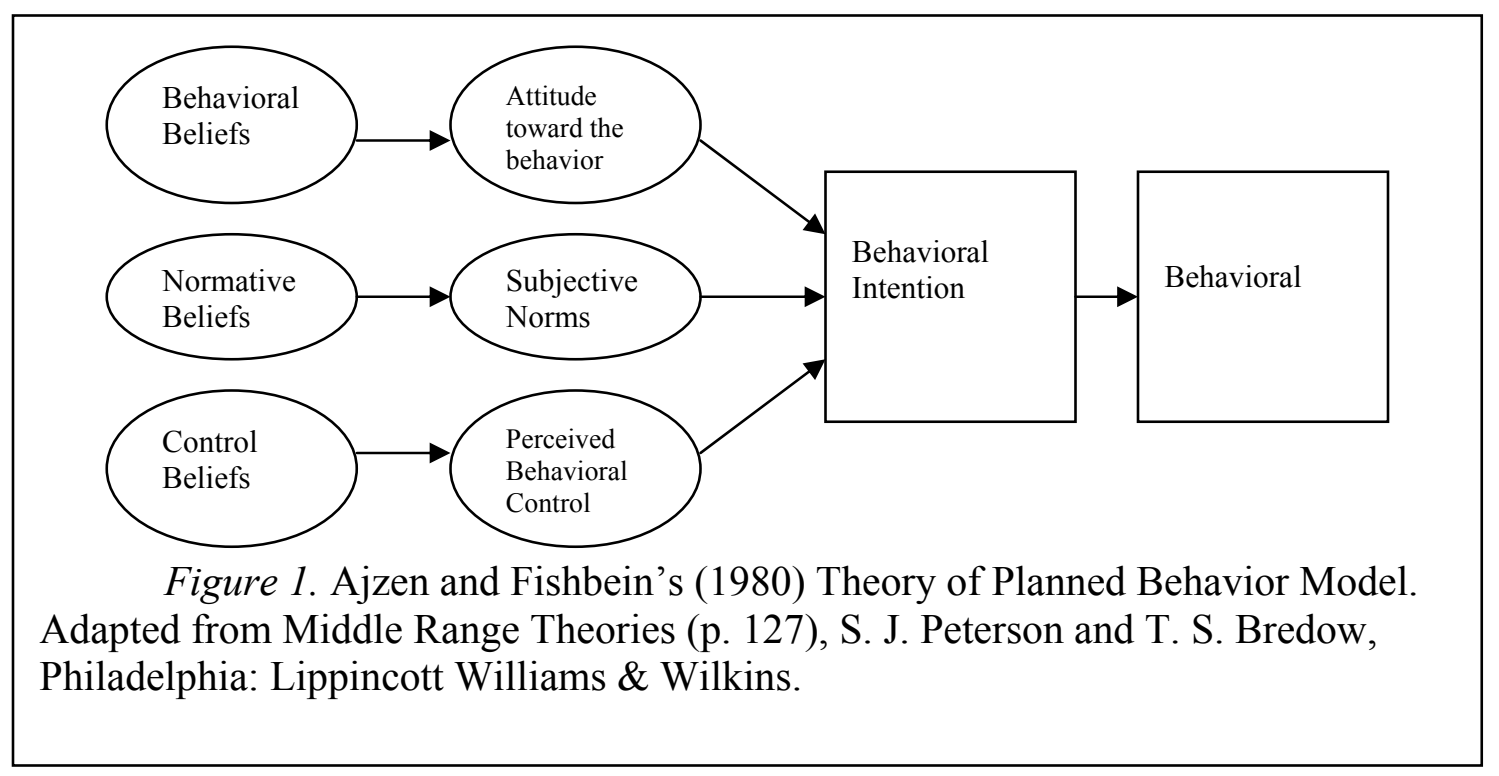




\section{Historical Background}

Ajzen and Fishbein developed the TRA in 1967. It is grounded in social psychology and is used to examine the relationships between attitudes and behavior. According to Peterson and Bredow (2004), the theory includes a principle of compatibility, which states that correspondence between attitudes and behavior will be greater when both are measured with the level of specificity regarding the four elements of action (behavior), target (performed on or toward a target), context, and time (specific time or occasion).

The theorists added a concept of behavioral intention as the proximal cause of behavior. "Behavioral intention is the person's motivation to engage in a specific behavior" (Peterson \& Bredow, 2004, p.128). The theory examines the interaction and influence of each construct on each other, but also looks at them individually. All constructs can play a meaningful role in behavioral outcomes (Ajzen, 1991).

After two decades, the original theorists, recognizing the limitations of the TRA, expanded the theory. The purpose of the extension was to overcome the limitation of the TRA which assumes that behavior is under volitional control; that there are no barriers to engage in an intended behavior. A third construct, perceived behavior control, was added because not all behavior is completely under volition. Perceived behavioral control explains the access to resources and opportunities to perform the behavior as well as the perceived power of various factors, which may inhibit or facilitate the behavior (Pender, Murdaugh, \& Parsons, 2006; Peterson \& Bredow, 2004; Zint, 2002). An example of this is a teacher who intends to refer a student for tutoring, however, does not refer because the teacher believes there is no support from administration for student tutoring. 


\section{Description of Theory of Planned Behavior}

The TPB is based on the assumption that rational considerations are a means of directing an individual's actions and decisions. These considerations are based on prudent and intentional contemplation. Behaviors depend not only on the person's decision, but also on skills and resources that are accessible. The theory addresses the issue of how difficult or easy it is to engage in a specific behavior (Pender, Murdaugh, \& Parsons, 2006; Peterson \& Bredow, 2004).

The specific theoretical constructs of TPB are thought to be antecedents to, and therefore, predictive of actual behavior for any social action. The theory has been found to be useful in predicting and understanding social behavior, which links the cognitive characteristics of individuals to their behavior (Ballone \& Czerniak, 2001; Peterson \& Bredow, 2004). It postulates that performance or non-performance of a behavior is a result of the intention of an individual toward that behavior (Charpentier, 1994). Intentions are assumed to identify the motivational factors that predict a specific behavior along with measuring the subjective likelihood that one will partake in a certain behavior (Ajzen, 1991; Charpentier, 1994; Peterson \& Bredow, 2004). Accordingly, the stronger the intention, the more likely it is that the behavior will occur (Peterson \& Bredow, 2004).

\section{Theoretical Constructs}

According to Davis, Ajzen, Saunders, and Williams (2002) human action is influenced by an attitude, behavioral belief, toward a behavior (a favorable or unfavorable evaluation of the behavior); the subjective norm (the perceived social pressure to perform or not to perform a behavior along with the beliefs about what others 
think about a behavior) and the perceived behavioral control (self-efficacy regarding the behavior). The TPB postulates that favorable attitudes and subjective norms, positively influence the person's perceived behavioral control (Peterson \& Bredow, 2004). The stronger the person's intention, the greater chance one will be motivated and willing to enlist in a specific behavior (Davis, Ajzen, Saunders, \& Williams, 2002).

Behavioral beliefs. Behavioral beliefs (attitudes) refer to how a person perceives the favorable or unfavorable consequences of his/her behavior. When an outcome of a behavior is perceived as being primarily desirable, the effect is a positive attitude; when an outcome of a behavior is perceived as being undesirable, the effect is negative (Peterson \& Bredow, 2004). The more classroom teachers believe they have support and feel positive about the consequences of performing a referral of a student for professional help, the more likely they may follow through with a referral; however, if they believe they do not have support and feel negative about the consequence of performing a referral, they may be less likely to refer students for help. If classroom teachers believe that they have adequate knowledge of ED symptoms and believe referring suspect students is part of their job responsibility, the outcome would positively affect the students. However, if they do not believe they have adequate knowledge of ED symptoms and do not feel referrals are part of their job responsibility, the outcome could negatively affect the students because teachers might choose to ignore impulses to refer students for appropriate counseling.

Normative beliefs. Normative beliefs, or subjective norms, refer to a person's perception of what others will think about his/her performance of the behavior, combined with the individual's motivation to comply with those impressions (Peterson \& Bredow, 
2004). Middle school teachers' perception of support or lack of support from administration, other teachers, school psychologists and social workers may influence their intention and actual behavior to refer students suspected of an ED for professional counseling.

Perceived behavioral control. Control beliefs (perceived behavioral control) refer to the person's perceptions regarding the degree to which they have control over performing a behavior. It also refers to the perceived means, opportunity, and the power over each factor necessary to facilitate or inhibit the behavior (Ajzen, 1991; Pender, Murdaugh, \& Parsons, 2006; Peterson \& Bredow, 2004). Perceived behavioral control refers to the individual's confidence that he/she is capable of performing the behavior successfully (Ajzen, 2002). If middle school teachers feel they have power and support they may refer a student suspected of an ED for help, which could positively affect the student academically, psychologically, and physically; if classroom teachers feel powerless and perceive they lack support, they may not refer students suspected of an ED for help and that could negatively affect the students academically, psychologically, and physically.

Behavioral intention. Behavioral intention is postulated to be the immediate antecedent to actual behavior. It refers to the degree of intent that the individual will engage in a behavior (Charpentier, 1994; Peterson \& Bredow, 2004). Peterson and Bredow (2004) defined behavioral intention as “the person's motivation to engage in a specific behavior" (p. 128). The harder one is willing to try to carry out a behavior, the more likely the behavior will indeed be performed (Peterson \& Bredow, 2004). If middle school teachers believe they should assist the identified student with an ED, they may 
engage in making a referral. On the other hand, if middle school teachers do not believe it is their responsibility to help the identified ED student, these teachers may not engage in making the referral, thus, possibly delaying interventions.

Behavior. Behavior refers to one's actual engagement in a particular course of action. Behavior is the transference of intention or perceived behavioral control into operation (Peterson \& Bredow, 2004). In this study, middle school teachers' actual action of referring students with an ED was surveyed.

The TPB provided a reliable framework to study the behavioral intentions of middle school teachers to refer students suspected of dealing with an ED to a professional counselor. The theory helped define and predict the behavior of the target population. Through the findings middle school teachers, administrators, and other school personnel will better understand those issues that impact a teacher's intention regarding referrals of students suspected of an ED for professional counseling. The schematic application of TPB is shown in Figure 2. 


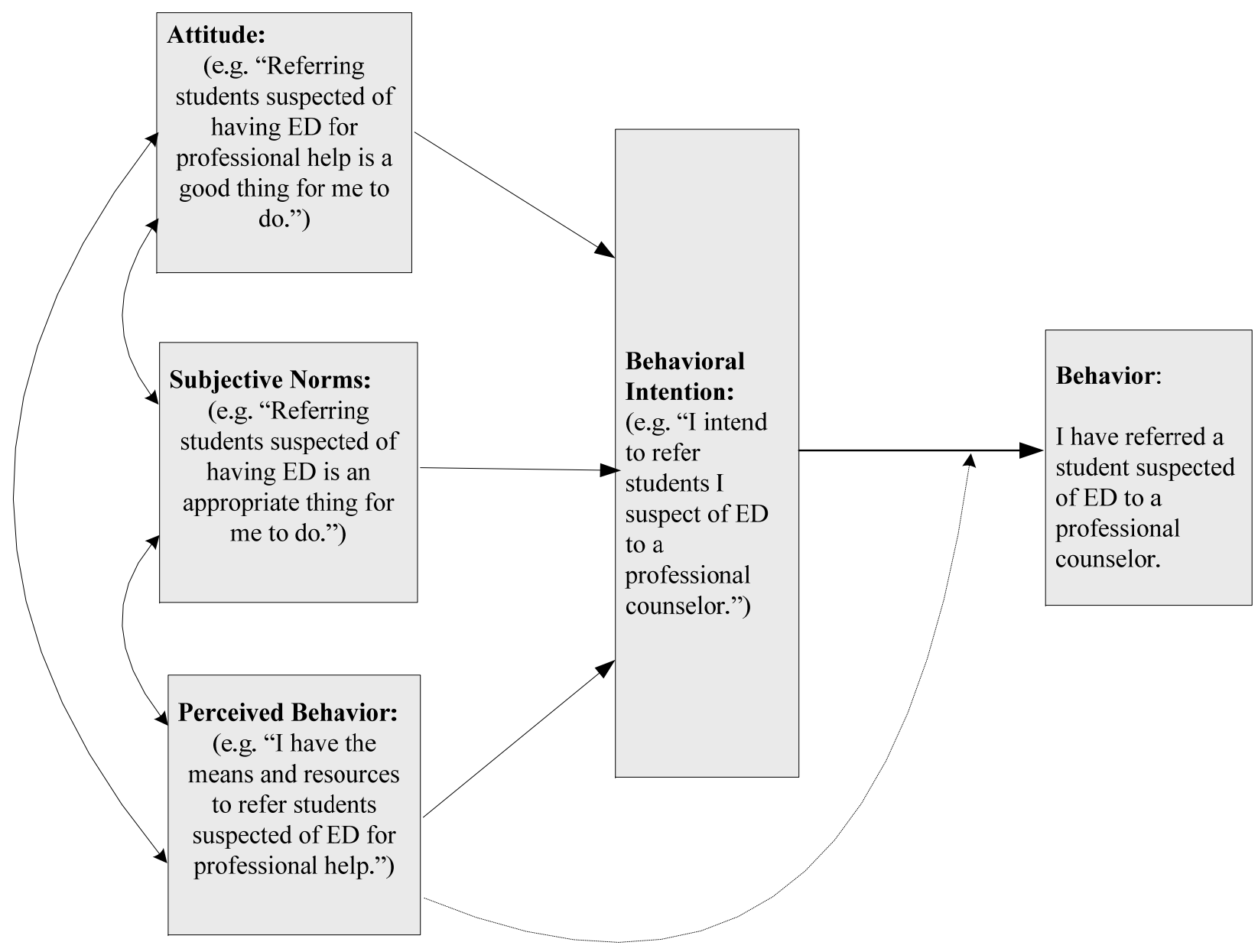

Figure 2. The representation of Ajzen and Fishbein's (1980) theory of planned behavior as adapted by D. Carr and applied to middle school teachers' attitudes, subjective norm and perceived controls as predictors of behavioral intention and actual behavior to implement referrals for students demonstrating signs of EDs. Shaded boxes are the focus of the study. 


\section{Relevance of the Theory to the Study}

The theory of planned behavior was developed to identify predictors of behavior in a variety of disciplines including business, healthcare and education. The theory examines the behavior intention and actual behavior in which an individual's behavior may not be in full volitional control (Peterson \& Bredow, 2004). Since the theory is utilized to predict a number of actual social behaviors, it was fitting to use it to examine the behavioral intention and actual behavior of middle school teachers toward initiating a referral for professional counseling for those students identified as being "at-risk" for an ED.

Inasmuch as teachers spend a great deal of time with students and are "...guided by rational considerations regarding the implications of their actions" (Peterson \& Bredow, 2004, p.127), it was most appropriate to use the TPB to better understand teachers' attitudes and beliefs about identifying students' suspected of an ED and referring them to a professional counselor. The TPB assumes that people are rational, give careful and deliberate consideration regarding the information available and that human behavior is not controlled by unconscious desires; thus, it was suitable to use it as a framework for this research study (Peterson \& Bredow, 2004).

\section{Delimitations of the Study}

This study only included middle school teachers teaching in school areas of one county, Broward, in south Florida. The subjects were selected to provide the best information to address the focus of the study (McMillan \& Schumacher, 2001). All the participants were volunteers. 


\section{Definition of Terms}

The following terms and phrases have special meaning and were used throughout this study. The definitions are intended to provide clarity.

\section{At-risk Student}

Those individuals for whom there is the high probability (risk) that negative consequences will occur if certain behavior changes do not occur (Dryfoos,1990). According to Stanhope and Lancaster (2008), risk refers to the probability that something will occur within a specified time period. The high-risk population, because of exposure, lifestyle, family history, context or other factors, makes this population at greater risk for a disease than the population at large.

\section{Eating Disorders}

Eating disorders are exceedingly negative responses to one's role in the world (Claude-Pierre, 1997). Two disorders, AN and BN, are classified as mental disorders in which individuals have disturbed perceptions about their body. They struggle with excessively eating too little, starving themselves, and eating chaotically with episodes of bingeing (Stanhope \& Lancaster, 2008; Videbeck, 2008).

\section{Anorexia Nervosa}

Anorexia nervosa is a life-threatening serious mental disorder in which an individual is totally absorbed and obsessed to keep his/her weight low and remain thin (McEwen, 2002). The inception is subtle and can be disguised as a way to be "fashionable" (Romeo, 1996). Anorexia nervosa is characterized by extreme weight loss, morbid fear of becoming fat, low self-esteem, distorted body image, bingeing, purging and an inability to recognize the seriousness of the condition (Videbeck, 2008; Webb, 
1994). The person may participate in excessive exercise and excessive, chronic use of laxatives, diuretics and diet pills. Emotionally, the person has a sense of low self-worth, compulsive drive for high achievement, depression and denial of hunger (Stanhope \& Lancaster, 2008; Videbeck, 2008).

\section{Bulimia Nervosa}

Bulimia nervosa is a condition in which an individual engages in inappropriate compensatory behaviors such as bingeing and excessive exercise to prevent weight gain. An individual usually engages in consuming large amounts of food, much larger than normal, and resorts to secret bingeing. Usually an individual is aware of the pathologic behavior yet still goes to great lengths to hide it from others (Videbeck, 2008).

\section{Attitude}

Attitude is theoretically defined as a person's overall positive or negative feeling about executing a behavior (Charpentier, 1994; Peterson \& Bredow, 2004). This term refers to a person's "perception regarding the consequences of the behavior and the evaluation of the consequences" (Peterson \& Bredow, 2004, p. 128).

\section{Subjective Norm}

Subjective norm is theoretically defined as a person's perceptions regarding what other significant individuals think if he/she performs or does not performs a certain behavior coupled with the individual's motivation to comply with that perception. Subjective norms assess the social pressure perceived by an individual (Peterson \& Bredow, 2004; Rhodes \& Courneya, 2003).

\section{Perceived Behavioral Control}

Perceived behavioral control is theoretically defined as a person's perception 
regarding the extent to which he/she has control over the decision to engage in the behavior (Peterson \& Bredow, 2004). In this study, it refers to the teachers' perception of how easy or difficult it is to identify a student with an eating disorder and to refer them to a professional for help.

\section{Behavioral Intention}

Behavioral intent is the individual's appraisal of the likelihood to engage in a specific behavior. It is theoretically the direct antecedent of actual behavior. The overall assumption is the harder a person is willing to try to perform a behavior, the more likely it will be performed (Peterson \& Bredow, 2004).

\section{Assumptions}

\section{Theoretical Assumptions}

The researcher assumed that:

- People are rational and make decisions based on available information.

- People think about implications and consequences of their actions before they decide to perform or not to perform a behavior.

\section{Research Assumptions}

It was herein assumed without evidence that:

- Teachers are directed by sound considerations regarding their actions.

- Teachers become involved in a behavior after careful and deliberate consideration is given to the available data.

- Behaviors such as identifying individuals at risk for EDs and referring those individuals for counseling are practical ways to assist students. 
- The participants completed the questionnaires for the study with honest answers.

\section{Summary}

Anorexia nervosa and bulimia nervosa are occurring more often in younger children than previously thought. The immediate and long-term effect of EDs can be devastating to individuals and their families and have negative implications for physical, emotional, psychological, and academic growth. Teachers' referring students suspected of an ED to professionals for counseling requires specialized training and acceptance of the responsibility to act.

\section{Overview of Chapters}

Research studies including those concerning intent, attitudes and perceived behavioral control reflected in the theory of planned behavior (Ajzen, 2004; Ajzen \& Fishbein, 1980) will be discussed in Chapter 2. Chapter 2 provides a review of the related literature and conceptual model of the study. Chapter 3 presents a detailed explanation of the methodological approach, research design, the instrumentation, the procedure to collect data along with protection of human subjects. Chapter 4 provides the reader with a discussion of the interpretation of data, analysis and evaluation of the data. Chapter 5 presents a discussion of the main findings of the data analysis, prior research, the implications of the study, limitations, and recommendations for future study. 


\section{CHAPTER II}

\section{REVIEW OF LITERATURE}

The literature search for this study was conducted in English from the fields of psychology, sociology, medicine and education. In spite of the broad inquiry in Dissertation Abstracts, Cumulative Index to Nursing and Allied Health Literature (CINAHL), Medline in Pubmed, Internet via Google search engine utilizing research studies, Wilson Select, and ProQuest, limited research information was retrieved. Books, theoretical articles, other dissertations and research studies were explored as well.

Empirical studies with respect to the use of the TPB to predict teachers' intention to identify ED students and intervene by referring them for professional counseling are needed. There are a number of research studies that use the TPB as a conceptual framework to explain teachers' behaviors. The literature review will describe the results of these studies in which TPB was used to predict teachers' attitudes, beliefs and intention to teach; the influences of TPB's primary constructs with teachers; and TPB's prediction of teacher's attitudes and beliefs regarding support from peers and administration.

\section{Theory of Planned Behavior Predictions of Teachers Intention to Teach}

Burak (2002) examined elementary teachers' intentions to teach health education utilizing theory of planned behavior. The purpose of the study was to test the applicability of TPB in the prediction of elementary teachers' attitudes, beliefs, intentions and behaviors to teach health education. A sample of 181 elementary teachers from the Commonwealth of Massachusetts, ranging from 22-60 years of age, who were enrolled in graduate educational research and teaching methods classes participated in the research 
study. The teachers completed an anonymous self-administered 44-item questionnaire. Ninety two percent were female, $96 \%$ White, non-Hispanic, and their average year of teaching was 11.83 . Thirty-three percent of the teachers never had a class in health or health education in their education courses. Those that did take a health class had only been enrolled once.

An instrument designed in 1986 using Likert-type items was constructed for this study using the guidelines suggested by Ajzen and Madden (1986). According to Fishbein and Ajzen (1975), the question of reliability posed no problem when measuring intention, attitude, and beliefs. An alpha coefficient of .95 for intention .88 for attitude, .83 for subjective norm, and .89 for perceived behavioral control supported their assertion. Multiple regression analysis was used to predict the teachers' intentions to implement health education in their classrooms.

The findings revealed that perceived behavioral control made the most substantial contribution when predicting the intentions of the teachers. Only $42 \%$ intended to teach health education. Fewer than $25 \%$ of the teachers believed they had adequate resources and material to actually teach health education. The TPB was found to be a valuable framework to examine and predict elementary teachers' intentions to teach health education.

Haney, Czerniak, and Lumpe (1996) explored the beliefs and intentions influencing teachers' intent to implement the four strands (science inquiry, scientific knowledge, conditions for learning science, and applications in science learning) of the State of Ohio's Competency Based Science Model into classroom instruction. The 
TPB was used to examine the three primary constructs (attitude toward the behavior, subjective norm, and perceived behavioral control) on teachers' intentions to engage in the targeted behavior.

A structured interview instrument was designed to access teachers' salient beliefs of attitude, subjective norm and perceived behavioral control that may have influenced their behavioral intentions. Four questionnaires were then designed for each strand of the Ohio Science Model.

Thirteen teachers, representing diverse populations, volunteered to participate in structured interviews to elicit salient beliefs regarding their attitudes, subjective norm, perceived behavioral control, behavior to engage in a specific teaching to include all the strands of the science model. The information obtained was then used to construct a research instrument that was used to obtain data from 800 Ohio teachers. A total response rate from the questionnaires was $52.5 \%$. The final sample consisted of 50 teachers at each grade level $\left(2^{\text {nd }}, 5^{\text {th }}, 8^{\text {th }}\right.$, and $\left.11^{\text {th }}\right)$.

Multiple regression and analysis of variance were used for statistical analyses. Significant findings suggested practical implications for science teachers' reform because teachers' attitudes toward implementing the strands of the model appeared to be a critical component to the educational change process. The results showed staff development opportunities needed to be addressed to foster positive attitudes toward any reform goals. The data also suggested that there was a lack of support structures to bring about changes in professional behavior.

Administrative, community support and involvement in the science reform were lacking, yet needed. The teachers' perceived that they did not possess the ability to bring 
about the educational change. The lack of effective staff development opportunities, available resources, and administrative support impeded their ability to bring about educational reform. The study's findings indicated that attitude toward the behavior held the greatest influence on the Ohio teachers' intent to implement all four strands of the Competency Based Science Model in their classrooms.

Crawley (1990) explored the utility of the TPB to predict the behavioral intentions of teachers in grades 5/6 or 9/10 who were enrolled in the Institute in Physical Science. Fifty teachers from both elementary and secondary schools, who were enrolled in The Institute of Physical Science, participated in the study to explore the utility to use investigative teaching methods.

An instrument was created utilizing the salient beliefs and referents from the targeted population. Simple and hierarchical regression analyses were used to determine the relative contributions of the three constructs of TPB to predict behavioral intention. Results of the study indicated that the three constructs made significant linear contributions to predict behavioral intention. Beta coefficients in the regression equations revealed the relative contributions of each variable to the prediction of behavioral intention ( $w_{1}=0.46, w_{2}=0.25$, and $w_{3}=-0.04$, respectively). Examination of the external variables revealed attitude toward the behavior to be the single most important predictor of behavioral intention. Teachers appeared to be in control to perform the use of investigative teaching techniques with little need for social support and ample resources and sufficient occasions to perform the behavior.

Lumpe, Haney, and Czerniak (1998) examined the factors that influenced kindergarten through twelfth grade (K-12) teachers' intention to use cooperative learning 
in their science classes. The TPB was used to identify the influences of three-based constructs on the teachers' intention and also aid in the identification of specific salient beliefs regarding cooperative learning. Differences in beliefs between the teachers' grade level assignment, years of experience, gender were also investigated.

Two separate groups of teachers were used for the study. The first group was used in belief identification and the development of the questionnaire. The second group, randomly selected teachers, was used to test the theory.

The first group consisted of 26 selected K-12 teachers from Ohio. The teachers were selected from a group of graduate level professionals attending a workshop on science teaching. The second group of teachers consisted of a sample of K-12 teachers from schools listed in the Ohio Schools Directory. A stratified random sample of 200 teachers was selected from this list. Questionnaires were sent out and 107 teachers returned the questionnaire, a 53.5\% return rate. Seventy-two percent of the respondents were females. Forty percent held graduate degrees, and the remaining $60 \%$ held bachelor's degrees. Ninety-one percent were Caucasian, $8 \%$ were African-American and $1 \%$ were Hispanic. The teaching experience varied: $20 \%$ of the teachers who returned the surveys taught $\mathrm{K}-2 ; 33 \%$ taught students in grades 3 through $6 ; 22 \%$ taught in middle schools, and $25 \%$ taught in high schools.

Descriptive statistics were calculated and a two-stage causal model was used to examine the potential influence of the theory constructs. One-way ANOVA was used to examine belief differences in grade level assignment and gender. Pearson correlation coefficient was employed to examine the relationships between beliefs and years they taught. Multiple regression models, ANOVA and correlation were calculated. 
The results about using cooperative learning revealed that teachers possessed positive attitudes. They perceived external support, professional development and resources as inadequate. Perceived behavioral control influenced teachers and had the greatest influence on their intent. Teachers felt that without support they would have difficulty implementing cooperative learning. There was negative correlation between grade level and intent to implement cooperative learning. Even though the result indicated that those teaching upper grades might not be as intent to use this type of learning, the study did reveal that there is a strong influence that beliefs play a role in the teachers' intent to use cooperative learning.

Zint (2002) conducted a study to predict science teachers' intention to incorporate environmental risk education in their teaching utilizing the theory of reasoned action (TRA) and TPB along with some determinants in the theory of trying (TT). The stratified random sample of grade 6 through 12 science teachers from Michigan, Ohio and Wisconsin Departments of Education participated. Questionnaires were sent to 2832 and less than 50\% (1336), were returned. A non-response survey revealed that many selected teachers were no longer teaching science in grades six through 12 . The mail survey's response rate was adjusted from $47 \%$ to $80 \%$. The majority of respondents $(69 \%, n=$ $922)$ were male and many completed coursework beyond the master's degree $(45 \%, n=$ $601)$.

Based on the findings, TPB augmented with past behavior and the theory of trying (TT) were the best theories to predict science teachers' intention to act, when the target behavior is not completely under their volitional control. The overall results suggested that perceived behavioral control is a valuable determinant when investigating the 
intention of science teachers' to act. Subjective norm was the weakest predictor of the science teachers' intention to act. Even though subjective norm was not as strong as perceived behavioral control, it did indicate that administrators, peers, students, parents, and other individuals believed professional development interventions should be implemented.

Martin, Kulinna, Eklund, and Reed (2001) examined determinants of teachers' intentions to teach physically active physical education classes (assuming that at least $50 \%$ of class time was used to engage students in moderate to vigorous physical activity). The TRA, TPB and self-efficacy models were used to investigate if teachers' intentions were governed by subjective norm, attitude, perceived behavioral control, and selfefficacy.

Six hundred and ninety physical education teachers from a Midwestern state were mailed material in the form of a survey for the study. The return rate of the surveys numbered 342 physical education teachers. The participants ranged in age from 23 to 62 years. There was representation from both genders with $41.1 \%$ females and $58.9 \%$ males. Educationally, the degree levels varied as follows: bachelor's degrees (36.5\%), master (56.2\%), specialist (6.7\%), and doctorate (0.6\%). Teachers averaged almost 10 years of experience and taught physical education either daily or twice a week. Using hierarchical regression analyses, the models of TRA and TPB were clearly supported by accounting for $65 \%$ of the variance in intention due to the main effect of attitude, subjective norm. The result of the regression analyses showed that the theory of selfefficacy and the role of perceived behavioral control failed to contribute to the prediction 
of intention. The indication was that attitude and subjective norm were predictive of the behavior of engaging in vigorous exercise during a physical education class.

Five of the research studies (Burak, 2002; Crawley, 1990; Haney, Czerniak, \& Lumpe, 1996; Lumpe, Haney, \& Czerniak, 1998; Martin, Kulinna, Eklund, \& Reed, 2001) followed the guidelines of Ajzen and Fishbein and developed an instrument for the study, and one study (Zint, 2002) did not fully describe if a previously developed questionnaire was used for the study. However, all of the six research studies used TPB as a framework and reported that attitude, subjective norm and perceived behavioral control was judged to be an effective theory for determining and predicting a teacher's behavior.

\section{Influences of TPB Constructs with Teachers}

The following research studies investigate the influence of TPB constructs on teachers' intention to act. The studies show that attitude, subjective norm, perceived behavioral control contributed to the behavioral intent of the teachers to implement new teaching strategies, to identify the need for more education regarding weight disorders, identify the need for more assessment skills and more education about referrals.

\section{Instructional Strategies to Meet Different Learning Styles}

Ballone and Czerniak (2001) used the TPB to investigate the influences of the primary constructs (attitude toward the behavior, subjective norm, and perceived behavioral control) that motivate teachers to implement a variety of instructional strategies to meet the different learning styles in the science classroom. Two samples of teachers were engaged in the study. The first group consisted of 28 teachers from urban,

rural, and suburban school districts in Northwest and Northeast Ohio. The second group 
consisted of randomly selected K-12 teachers in the 18 county northwest region of Ohio. A mailing list of schools was obtained from the Science, Mathematics, and Technology Education Center at the University of Toledo. Teachers' names and addresses were acquired from those that received the Science, Mathematics, and Technology Education Center quarterly newsletter. A random sample of 250 names out of 4,200 names was selected for this mailing. One hundred ten surveys were returned yielding a $44 \%$ return rate. Teaching experience from the sample ranged from one to thirty-seven years. Twenty-one percent had 0-10 years of experience, $45 \%$ had $11-20$ years of experience, $33 \%$ had 21-30 years of experience, and 1\% reported more than thirty years of experience. Fifty-four percent held a master's degree, $45 \%$ held bachelor's degrees and $1 \%$ had a doctorate or specialist degree. Sixty percent of the females responded. Teachers (K-4) represented $27 \%$ of the sample; intermediate (5-8) represented $33 \%$ and $39 \%$ were high school teachers. Ninety five percent were Caucasian/White, $3 \%$ were African American, 1\% were Hispanic and 1\% revealed the category "other."

Reliability for the indirect attitude, subjective norm, and perceived behavioral control scales were calculated using Cronbach's alpha internal consistency coefficient and the results were: attitude $(\mathrm{ABI})=.59$, subjective norm $(\mathrm{SNI})=.83$, perceived behavioral control $(\mathrm{PBCI})=.83$. Content validity was inferred from the indirect measures from the salient beliefs that came from the teachers' responses to the openended questions and from the significant correlation's between the direct and indirect measures of $\mathrm{ABI}, \mathrm{SNI}$, and $\mathrm{PBC}$ constructs.

The results disclosed that attitude was the strongest influence on the teachers' intent to implement a variety of instructional strategies to meet the different learning 
styles in the science classroom. The findings also revealed that teachers should be involved in positive experiences to show that a variety of strategies can be implemented in their classrooms. Further, findings also indicated that teachers should be provided with concrete and successful experiences through pre-service training and through on going staff development. Active participation and decision-making will benefit teachers by exhilarating and empowering them. Opportunities to build teachers skills and understanding through workshops were also identified through the study. In addition, the results indicated a need for necessary curricular information. Successful implementation with materials would yield positive attitudes, which would help to reinforce the reformed recommendations.

The subjective norm contributed significantly toward behavioral intent. The findings revealed that teachers believe that those who are important to them influence their intent to implement the varied strategies. Results revealed administration should be actively involved. Collaboration with other teachers and other resource personnel would also be beneficial.

Perceived behavioral control beliefs did not significantly contribute toward intent. This finding suggested teachers did not feel they had staff development opportunities and resources available to them. As a result they felt curriculum reform would not be easy but valuable.

The studies affirmed that teachers' beliefs were critical components in the classroom (Crawley, 1990; Haney, Czerniak \& Lumpe, 1996; Lumpe, Haney, \& Czerniak, 1998; Pajares, 1992 as cited in Ballone \& Czerniak, 2001), therefore, supporting the idea that this theory would be a valuable framework to better understand 
middle school teachers attitudes, beliefs, perceived behavioral control, behavioral intention and actual behavior when addressing the ED students in their classroom.

\section{Teachers Attitudes and Beliefs Utilizing TRA and TPB}

Burak (1994) examined teachers' beliefs and attitudes toward AIDS and students with HIV/AIDS. Burak reported that previous studies did not address specifically the teachers' intentions and attitudes toward teaching HIV/AIDS education. The TRA and TPB was the framework for the study. A sample of 198 elementary school teachers working in the Commonwealth of Massachusetts completed a self-administered questionnaire. Multiple regression analysis was used to predict intentions to teach about HIV/AIDS as well as identify the determinants of intentions. Attitude, subjective norm, perceived behavioral control explained $64 \%$ of the variance in regard to the teachers' intentions; perceived behavioral control contributed the greatest weight to the prediction.

\section{Teachers Attitudes and Beliefs Regarding Support}

Dee, Henkin, and Pell (2002) identified variables associated with perceived support for innovation among elementary teachers. The study was conducted at a large urban school district in the Southeastern part of the United States. Eleven elementary schools using site-based management were randomly selected for the study. Full-time teachers $(N=517)$ were in the randomly selected schools. Responses $(N=295) 57.1 \%$ were analyzed. A 61 item self-report instrument, the Siegel Scale of Support for Innovation, was used.

Results indicated that teachers who perceived support for innovation also reported clearly delineated responsibilities, positive communication with colleagues, and no 
constraints of the content of their teaching. Teachers' perceptions of support for innovation were very important in site-based managed schools.

The positive influence of TPB primary constructs with teachers was ascertained in the studies of Ballone and Czerniak (2001), Burak (1994) and Dee, Henkin and Pell (2002). The results of the TPB predicted that attitude was one of the strongest influences on teachers' intent to educate, therefore, supporting the use of TPB to predict middle school teacher's attitudes regarding these debilitating diseases which could affect their student's academic progress.

\section{Teachers' Role with Eating Disordered Students}

The following seven studies did not utilize TPB to explore the research topics; however they provided valuable information regarding teachers' roles with ED students.

\section{Coaches Attitudes, Understanding, and Personal Experiences with ED Students}

Griffin and Harris (1996) surveyed a group of junior high and high school coaches concerning their attitudes, knowledge, personal experiences and suggestions regarding weight loss and found $20 \%$ female athletes needed to lose weight. Sixty-four percent of the coaches reported that weight of the athletes was extremely important. The researchers reported $71-84 \%$ of the coaches agreed that having knowledge about weight control is definitely important; however, the coaches did not demonstrate a high level of understanding when quizzed on the topic. A total of $23 \%$ of the coaches replied "yes" or "probably yes" when asked if students had an eating disorder; however, they did not refer these students to counseling for help with weight issues.

The study showed that the junior high and high school coaches lacked knowledge about nutrition, body weight and EDs. In addition, the coaches demonstrated an inability 
to detect EDs. Finally, the study reported a tremendous need to educate coaches on signs and symptoms and information for proper referrals.

\section{Teachers' Role with Prevention for Students EDs}

Teachers, as well as counselors, should be aware of the complex nature of eating disorders so they can fulfill their role with prevention efforts (Natenshon,1996). In the growing literature on prevention of $\mathrm{AN}$ and $\mathrm{BN}$, the actual role of the teacher is sparse. According to Piran (2004a) three surveys have been conducted with teachers about their role with prevention of $\mathrm{AN}$ and $\mathrm{BN}$.

Neumark-Sztainer, Story, and Coller (1999) conducted the first survey, which focused on the teachers' role in weight-related disorders. There were 114 high school personnel of whom $75 \%$ were teachers of science, health, home economics and physical education. The teachers expressed an interest in learning about prevention tools $(72 \%)$ and had an interest in learning methods to discuss this issue informally with students (71.3\%); they preferred that prevention information be integrated into the curriculum (67\%) rather than conducting prevention programs.

Smolak, Harris, Levine and Shisslak (2001) examined the preferred format of materials relevant to prevention of eating EDs among teachers (23 high school teachers, nine middle school teachers and eight elementary school teachers). These teachers wanted brief information regarding signs and symptoms of EDs (70\%) and information on how to help students who appear to have an eating problem (63\%). Fifty-six percent of the teachers utilized school resource persons for assistance.

Rayman and Piran (2002) conducted a survey with 33 elementary teachers who instructed students in fourth, fifth, and sixth grades. The focus of the survey was to 
address teachers about their actual practices along with their needs and barriers, regarding the prevention of these disorders. The results indicated that most teachers $(95 \%)$ addressed healthy eating with students. Only $52 \%$ of those teachers addressed body image issues and only $24 \%$ of the teachers focused on the harmful consequence of dieting; $14 \%$ discussed EDs with the students. Eighty-seven percent of the teachers were interested in relevant workshops and procuring additional resources (76\%) and 21\% desired having guest speakers. There was a gap in relation to the role of teachers related to body image. Most teachers (57\%) felt they were positive role models to their students. One third of the teachers believed professional support would enhance their impact on the student. Most teachers (69\%) encountered student-peer teasing about weight; only $32 \%$ tried to address weight-related teaching with their classes. They also found that no school had policies regarding weightism.

As a result of the three surveys conclusions were drawn: there was an interest in ED prevention by school personnel; there was an interest in training that would encourage constructive interactions between teacher and student in the areas of body image, role modeling, peer teasing, and school policies; and there was an interest of adding and integrating prevention in the existing curriculum along with receipt of ED material and support (Piran, 2004a).

\section{Early Identification of Students with Anorexia Nervosa and Bulimia Nervosa}

Judge (2001) studied a national sample of 500 school psychologists to examine their ability to identify distinguishing characteristics of EDs, the factors that preempt or exacerbate these disorders, along with the services provided for students with AN and BN 
by the school psychologists. Five hundred participants were contacted of which 284 were completed and 218 were identified as useable.

The study's results reported that school psychologists had adequate knowledge regarding the characteristics of AN along with risk factors for the development of EDs. However, only a small percentage of them intervened with students. Data suggested they were unable to provide interventions due to perceived lack of interventions, assessment, skills, time, and referrals. Those that did intervene, which were few, only provided indirect services. The findings identified that there are important implications for knowledge and service provisions and future research.

Layton (2003) researched the experiences of 10 secondary school teachers regarding early identification EDs. The qualitative study identified that teachers had similar challenges when attempting to identify depression in students. Facilitative factors included close student teacher relationship, overt symptoms and personal mental health conditions. Distant student-teacher relationship, a lack of knowledge regarding EDs and hidden symptoms were identified as barriers. Of the teachers interviewed, physical education teachers were the ones that referred students for help. Teachers who were able to identify students with EDs did not take action because they felt it was not appropriate to intervene. Teachers also wanted to wait to see if the problem became more evident before referring for fear of breaching trust. An implication for future research suggested that there needs to be more training for identifying these issues as well as for systemic changes that will enhance a teacher's comfort level with referrals. 


\section{Discussion}

The TPB has been used to examine the influences of attitudes, subjective norms, and perceived behavioral control in predicting individual behaviors (Ajzen, 2001b). The results from the literature review indicated that the TPB was a reliable framework to evaluate the predictors in educational research. There were six research studies that used TPB as a framework. Five of the research studies (Burak, 2002; Crawley, 1990; Haney, Czerniak \& Lumpe, 1996; Lumpe, Haney \& Czerniak, 1998; Martin, Kulinna, Eklund \& Reed, 2001) followed the guidelines and procedures of the TPB for their studies. The results of the five studies demonstrated that the constructs' influences could be assessed and were significant predictors of teachers' intentions to teach a variety of issues. There was only one study by Zint (2002) who used the TPB that did not describe how the questionnaire was developed and whether the guidelines and procedures were followed according the guidelines of Ajzen.

The positive influence of the TPB primary constructs with teachers in the studies of Ballone and Czerniak (2001) and Burak (1994) supported the idea of using TPB in this study. The theory did predict that attitude influenced teachers and their intent to act, utilizing the theory to examine middle school teachers' attitudes and beliefs about referring ED students to a professional counselor. These predictions provide a valuable framework for this study.

There were seven studies (Burak, 1994; Dee, Henkin, \& Pell, 2002; Griffin \& Harris, 1996; Judge, 2001; Layton, 2003; Neumark-Sztainer, Story, \& Coller; Rayman \& Piran, 2002; Smolak et al., 2001) that did not utilize TPB to explore related research 
topics; however, they provided valuable information regarding the teacher's role with ED students, which support this investigation.

The findings of two studies (Judge, 2001; Layton, 2003) demonstrated a definite need for more educational programs for teachers to increase the teacher's knowledge base of AN and BN. The findings also identified a need for educational programs to better understand the referral process.

The TPB has been shown to be a successful theory, one that deals with a relatively broad scope of phenomena that covers a limited range of phenomena of concern within a particular discipline, and allows generalization and operationalization (Mc Kenna, 1997; Peterson \& Bredow, 2004). The studies had acceptable sample sizes, response rates and statistical tests. However several of the samples within the literature review had a small percentage of Hispanic or African American population represented and conducting the present study in south Florida will provide a wider representation of these two cultures. Understanding the constructs' important contributions and their relationship between attitudes and behaviors could expand the knowledge of middle school teachers (Peterson \& Bredow, 2004) regarding recognizing signs of AN and BN and then referring suspect students for professional counseling. Applying this theory to study the intention of middle school teachers' to refer students suspected of an ED should bring a clearer picture of the barriers, internally and externally, that prevent teachers from being as effective as they could to assist these troubled students.

\section{Summary}

The TPB provides a theoretical framework to understand the relationship of the constructs of attitude, subjective norm and perceived behavioral control as antecedents to 
behavior intention as well as the antecedent of actual carried out behavior. Very little is known regarding teachers' attitudes, subjective norms, perceived behavioral control, behavioral intent, or behavior regarding the issue of middle school teachers' identification of students with an ED and referrals to professional counselors, particularly for those students demonstrating signs of AN and BN.

This study used a previously tested instrument Bagnardi (2006) which examined the same constructs, behavioral beliefs (attitude), subjective norm (peer influence), perceived behavioral control (resources/confidence) and behavioral intent with teachers (university faculty). In this study the instrument was adapted and it will be used to collect data from a sample of the target population of teachers (middle school teachers).

The testing for this study examined how all three TPB theoretical constructs together predict behavioral intent of middle school teachers to refer suspected ED students to a professional for counseling. The constructs, independently of the other two, will be tested to see if they account for a significant amount of unique variance in the prediction of the criterion variable (i.e., behavioral intent to refer). In addition, the testing will examine how well each of the constructs predict the behavioral intent of the middle school teachers to refer. The results will have implications in the areas of middle school education, middle school research and middle school practice. Additionally, the understanding gained will be used to support middle school teachers in their efforts to have a direct and positive influence on the health promotion and illness preventative behaviors of an ED by referring suspected students to a professional for counseling. 


\section{Overview of Chapter 3}

In Chapter 3 the specific method, design, and procedure for researching this topic are described. Specifics regarding the collection of data, along with procedures for protecting of human subjects and statistical analysis procedure will be presented. 


\section{CHAPTER III}

\section{METHOD}

The researcher examined the relationship of the three major constructs, attitude, subjective norm, and perceived behavioral control of the TPB, and its efficacy in predicting the behavioral intent and actual behavior of middle school teachers in referring students suspected of having AN and BN. The theory was selected because it has been widely used for predicting individual behaviors (Ajzen, 2001b). Based upon the research questions, three hypotheses were posed for the study:

Hypothesis 1 suggested that there was a statistically significant relationship, uniquely and as a linear composite, between the theoretical constructs, attitude, subjective norms and perceived behavioral control and the behavioral intent of middle school teachers to refer suspected AN and BN students for professional counseling.

Hypothesis 2 suggested that there was a statistical difference in the mean scores for behavioral intent between middle school teachers that reported having ever referred a student suspected of having AN and BN and those middle school teachers that reported not having made such a referral.

Hypothesis 3 suggested that there was a significant proportion of unique variance each of the three constructs, attitude, subjective norms, and perceived behavioral control, contributed to predicting teacher intention to refer.

\section{Research Design}

The basic design for this study was ex post facto method. According to Kerlinger (as cited in Cohen, Manion, Morrison, \& Falmer, 2000) ex post facto design is systematic in that the independent variables have already occurred and can not be manipulated or 
controlled by the researcher. The researcher studies the variables retrospectively for a possible relationship to, and effects on, the dependent variable or variables. Ex post facto research demonstrates relationships and not causation (Lord, 1973; McMillan \& Schumacher, 2001; Newman \& Newman, 1994).

Ex post facto research is an appropriate design if questions of a study focus on relationships (Newman \& Newman, 1994). In this study the researcher's focal point was to examine the relationship of the constructs of attitude, subjective norm, and perceived behavioral control of middle school teachers were antecedents to their behavioral intention of referring students suspected of having an eating disorder for professional counseling. The researcher also examined the measure of behavioral intent between middle school teachers that reported having ever referred a student suspected of an eating disorder and those middle school teachers that reported not having ever made such a referral.

\section{Setting}

Data were collected from volunteer teachers employed at public middle schools in Broward County in south Florida. Broward County has 41 middle schools employing over 3,000 middle school teachers. The district is divided into 6 areas identified as Central East, Central West, North East, North West, South East and South West. These district areas are densely populated and home to a large number of diverse populations. Focusing on one school district helped increase the response rate. Targeting middle school teachers in the selected schools in Broward county aided in obtaining a larger sample. 


\section{Sample}

The population of interest for this study was middle school teachers. A convenience sample, a non-probability method of selecting subjects, was used on the basis of availability and accessibility (McMillan \& Schumacher, 2001). The sample of at least 105 middle school teachers were to be recruited for the study from the six areas within Broward County public school system, some based on the researcher's contacts within the areas that assisted with recruiting teachers. The researcher recruited 115 volunteers for the study.

\section{Inclusion/Exclusion Criteria}

Only classroom teachers providing instruction in middle schools in Broward County were included as participants; teachers outside these geographic areas or grade levels were excluded. Eligibility was assured by responses provided on the demographic portion of the research questionnaire.

\section{Protection of Human Subjects}

The safeguards for protection of human subjects were employed throughout the entire study. Prior to data collection, approval to conduct the study was acquired from the Florida International University Institutional Review Board (IRB). Approval to conduct the study in the middle schools with the teachers was obtained from the Research Department of the School Board of Broward County.

Informing Participants. Participants were anonymous in that their identity was unknown to the researcher or anyone else with access to the data. A cover letter was provided to potential participants (Appendix A). The cover letter explained the purpose of the study, name of the researcher, ability to withdraw, and the researcher's 
organizational affiliation. There was a limited withdrawal opportunity once the questionnaires were co-mingled because there was no way to identify individual forms since the participants were anonymous.

Potential Adverse Consequences and Benefits of Participation. There were no anticipated risks associated with participation. While there was no immediate or direct benefit to participants, the results might help in the understanding of the factors that influence the decision of middle school teachers to refer students suspected of having an ED.

File Storage. Completed questionnaire forms are retained in a locked file cabinet in the researcher's home office. Computer files are stored on the researcher's home computer which is password protected and secured by firewall software. Only the researcher and a statistician have access to the raw data. These files will be retained for a period of 5 years. At the end of the fifth year, all questionnaire forms will be shredded and computer files will be deleted.

\section{Determination of Sample Size}

To determine an adequate sample size for the number of variables and the statistical techniques that were employed, a priori estimation of sample size was made based on a power analysis. Sample size is related to power, effect size, and significance level (Mertler \& Vannatta, 2002; Munro, 2005). Based upon Cohen (1977) and McNeil, Newman, \& Kelly (1996) a power of approximately .86 was estimated for detecting a medium size $\left(f_{2}=.15\right)$ effect at an alpha level .05 , the optimal sample was $n$ of 105 with five predictor variables. 
Hypothesis 1 suggested that there was a statistically significant relationship, uniquely and as a linear composite, between the theoretical constructs, attitude, subjective norms and perceived behavioral control and the behavioral intent of middle school teachers to refer suspected AN and BN students for professional counseling. The relationship among the variables was tested by multiple regression; a sample size of 114 was used.

Hypothesis 2 suggested that there was a statistical difference in the mean scores for behavioral intent between middle school teachers that reported having ever referred a student suspected of having AN and BN and those middle school teachers that reported not having made such a referral. Discriminant analysis was used to assign the two groups, those that suspected and referred and those that suspected and did not refer, and the differences were then tested.

Hypothesis 3 suggested that there was a proportion of unique variance that each of the three constructs: attitude, subjective norms, and perceived behavioral control, contributed to predicting teacher intention to refer. Multiple regression was used to determine the amount of unique variance that each of the constructs contributed to predicting teacher intention to refer.

\section{Instrumentation}

The instrument for this study was adapted from an already created instrument (Bagnardi, 2006) which followed the guidelines of (Ajzen, 2001a; Ajzen, 2004). The formerly tested instrument was used to measure and study the same constructs among a group of university faculty (teachers) regarding their intention to use service learning for students (Bagnardi, 2006). 
The dissertation committee, an expert panel of educators, along with a statistician reviewed the previously used survey instrument and found it was logically appropriate for the target population. The instrument was adapted, and has herein been modified for use with the target population of middle school teachers to explore their behavioral intention and actual reported behavior of using the referral process for students they suspected of having an eating disorder (Appendix B).

Bagnardi (2006) subjected the instrument to test of reliability and reported results of alpha coefficients of .90 for behavioral beliefs (attitudes), .91 for subjective norm beliefs (influences of others), .87 for perceived behavioral control beliefs (resources), and .97 for behavioral intention. In this study, the instrument's tests of reliability and reported results of alpha coefficients were: behavioral beliefs (attitudes) .85 , subjective norms beliefs (influence of others) .91, perceived behavioral control beliefs (resources and confidence) .72 , and .95 for behavioral intention.

\section{Scoring}

All items on the scales for attitude, subjective norm, perceived behavioral control, and behavioral intention to make such a referral in the future provided the participant with a 7-point Likert scale for a response. Each scale was summed for a composite score with higher scores indicating a more favorable attitude, a stronger level of subjective norm, perception of more personal control over the behavior, or a more positive intention.

Attitude. Attitude, the favorable/unfavorable attitude towards a behavior, was scored by the participants' responses. There were eight semantic differential items and three statements, numbered from 1 to 11 . Possible scores ranged from 11 to 77 using the Likert scale 1-7. 
Subjective norm. Subjective norm, social pressure to perform or not perform the target behavior was scored based on the participants' responses. There were 9 items, numbered from 12 through 20. Possible scores ranged from 9 to 63 using the Likert scale $1-7$.

Perceived behavioral control. Perceived behavioral control, people's confidence that they were capable of performing the target behavior, was scored based on the participants' responses. There were 11 items, numbered from 21 through 31. Possible scores ranged from 11 through 77 using the Likert scale 1-7.

Behavioral intention. Behavioral intent, the person's motivation to engage in a behavior, was scored based on the participants' responses. There were 3 items, numbered 34 through 36. Possible scores ranged from 3 through 21.

Reported past behavior. Two questions were added to identify past reported behavior of the participants. The response to the questions 32 and 33 was a "yes" or "no." One question numbered 33 had a follow up question of what factors facilitated or inhibited the teacher's referral of a student with suspected AN or BN.

\section{Procedure}

After approval from Florida International University's Institutional Review Board (IRB) and the Broward County School Board, the researcher began the process of collecting data. To explain the study and obtain approval to distribute the questionnaires and demographic surveys, the researcher contacted the middle school principals who were approved by the Research Department, Broward County, Florida.

The researcher first contacted the principals at two year-round schools, McNicol Middle School and Gulf Stream Middle School. These middle schools were selected 
because their teachers would be in session longer than the other teachers in the middle schools and they would return earlier in the fall than the other middle school teachers in the county given that they are year-round schools. The only year-round school used in the study was Gulf Stream Middle School. Unfortunately McNicol Middle School was not used because an appointment with the principal could not be arranged.

Gulf Stream Middle School's principal met with the researcher and approval for the distribution of questionnaires was agreed upon along with naming a contact person. A convenient date for distribution of flyers was selected (Appendix C). The researcher discussed the process of distribution of flyers and questionnaires to the contact person. The contact person would place the flyers and questionnaires in each teacher's mailbox on the selected date of distribution. Each questionnaire included a cover letter explaining the purpose of the study to the participants.

The teachers were allocated 7 school days to complete the questionnaire. A specific box/container was provided to the contact person to collect the questionnaires. Three days prior to collecting the questionnaires, the researcher spoke with the contact person to provide a flyer to remind the teachers of the collection date (Appendix D). The contact person at Gulf Stream Middle School informed the researcher that the reminder flyer was not needed. On the day after the due date the researcher picked up the questionnaires.

The researcher contacted the office managers at Olsen Middle School, Pioneer Middle School, Indian Ridge Middle School, and Nova Middle School to arrange an appointment with the principals in pursuit of collecting the 105 usable questionnaires. These schools were selected based on the researcher's contacts that could assist with 
recruiting teachers. Once approval was received from the individual principal at the school, the same process mentioned previously was used to distribute and collect the questionnaires.

Since the required number of 105 usable questionnaires were not collected from the teachers in these aforementioned middle schools, the researcher had to submit another request to the Research Department at the Broward School Board. The approval process to contact more principals in the county took additional weeks which caused a delay in the distribution of the questionnaires. After permission was granted to contact the principals, the researcher contacted office managers at Seminole Middle School, Walter C. Young, Middle School and Plantation Middle School. The same process with regard to contacting principals for permission, distributing and collecting the usable questionnaires was used as in the previously mentioned schools until the total of at least 105 was reached. The usable amount of 114 questionnaires were collected so further contacts were not made to distribute more questionnaires.

\section{Statistical Analysis Plan}

\section{Data}

All questionnaires were examined for completeness. Only completed scales were included in the analyses. There was consideration for those questionnaires in which scales were incomplete. However, when the participant provided an incomplete response on one of the scales, but completed responses to other scales then, the completed scale was used for reliability testing.

A quality check procedure was conducted to minimize data transcription error.

Responses to each item of each scale was entered into the Statistical Package for the Social Sciences (SPSS) for Windows v.19.0 (SPSS, 2007). The responses to the 
individual scale items were entered into the data matrix and computer scores for the scales were calculated. Additionally, each scale was manually summed. The manual sums were subtracted from the computer calculated scores. The result of zero assured accurate data entry.

\section{Descriptive Statistics}

Descriptive statistics were used to describe the characteristics of the sample. The external variables including age, race, ethnicity, and highest degree held were included. The descriptive statistics were used to provide measures of central tendency for the scores of each of the construct scales.

\section{Reliability}

The instrument used previously to collect the data from a sample of university teachers demonstrated strong internal consistency. It had not been used prior to this study to measure the constructs among middle school teachers to refer students suspected of eating disorders. Therefore, data obtained was subjected to reliability testing by means of Cronbach's alpha. Cronbach alpha is the most appropriate type of reliability for a research questionnaire in which there is a range of possible answers for each item. It is used as an estimator of the internal consistency reliability of a psychometric test score for a sample of examinees (McMillan \& Schumacher, 2001). Cronbach's alpha, coefficients, were calculated for the individual scales for attitude, subjective norm, perceived behavioral control and the entire scale (McNeil, Newman, \& Kelly, 1996). Criterion used to identify poorly functioning items was a corrected inter-item correlation of $<.30$. The acceptable alpha coefficient for each scale was set at .70 (Nunnally \& Bernstein, 1994). 
When the data for the dependent variable was not normally distributed attempts were made to transform the data. Linear transformations are used to find weights in which there are several independent variables to predict a single dependent variable when multiple regression is used (Stockburger,1998). According to Field (2005), there are three transformations that may be used: log transformation, square root transformation, and reciprocal transformation. If transformation fails to correct skewed data, parametric testing will be abandoned and non-parametric testing will be used. In the case of this study parametric testing was not abandoned.

\section{Validity}

Validity is a criterion for evaluating a quantitative instrument. It is the degree to which an instrument measures what it is expected to quantify (Ajzen, 2004; Polit \& Beck, 2004). Since the instrument in this study had been adapted and not developed by utilizing group interviews with the targeted population and receiving feedback from experts, validity was considered a limitation.

\section{Quality Assurance}

The relationship between the theoretical constructs was analyzed by means of parametric tests; therefore, the data met specific characteristics. Assumptions necessary include that the data are normally distributed; that there is homogeneity of variance; that data are measured at the ordinal level; and that the data are independent, that is, the behavior of one participant does not influence the behavior of another. Prior to testing, diagnostic methods were conducted to make sure none of these assumptions were violated. 
Several techniques were employed to make sure that the data conformed to the assumptions for parametric testing. To assess if the data were normally distributed histograms with the normal curve line imposed were visually inspected for each variable. Additionally, the Kolmogorov-Smirnov $(D)$ statistic was calculated considered; a nonsignificant value $(p>.05)$ supported normality. Values for skewness and kurtosis were generated; values approximating zero indicated distribution normality.

A residual plot assessed the linear relationship between the independent variables and the dependent variables and support homosedasticity. Collinearity statistics for tolerance and variance inflation factor (VIF) was considered. Indicators for multicollinearity will be tolerance $<.1$ and VIF $>10.0$ (Cohen, Cohen, West, \& Aiken, 2002; Pedhazur, 1997; Vogt, 2005).

Outliers were defined as any score falling below or above 3 standard deviations $(S D)$ from the mean $(M)$ and identified by boxplots. Outliers were examined to determine if they were properly part of the population from which the sample was intended. Since they were part of the target population, they remained in the analysis, but steps were taken to reduce their impact. Following the guidance of Tabachnick and Fidell (2001) for variable transformation, scores for the outlying cases were assigned a raw score that was one unit larger or smaller than the next most extreme score in the distribution.

\section{Hypothesis Testing}

Three research hypotheses were posed. Hypothesis 1 examined if there was a statistically significant relationship, uniquely and as a linear composite, between the theoretical constructs, attitude, subjective norms, and perceived behavioral control and 
the behavioral intent of middle school teachers to refer suspected AN and BN students for professional counseling. There were three independent variables, considered as predictors, and one criterion variable identified. Multiple correlations were used to test the hypothesis.

Vogt (2005) suggested that regression analysis can be used to explain the "nature and closeness of the relationship between two or more variables, specifically, the extent to which you can predict some by knowing others and the extent to which some are associated with others" (p. 269). In this study, regression analysis was used to assess the degree to which the dependent (outcome) variable was related to the independent (predictor) variables. Regression analysis was used to predict the score of the dependent (outcome) variable from scores on several independent (predictor) variables. The three constructs were examined to ascertain if all three constructs together predict behavioral intent to refer. The researcher also tested whether each construct, independently of the other two, accounted for a significant amount of unique variance in the prediction of the criterion variable that is behavioral intent to refer. The testing was used check if each of the three independent variables predicted the criterion variable.

Hypothesis 2 examined if there was a statistical difference in the mean scores for behavioral intent between the middle school teachers that reported having ever referred a student suspected of having AN and BN and those middle school teachers that reported not having made such a referral. The difference in the scores between the two groups were tested by means of discriminant analysis.

Kerlinger and Lee (2000) suggested that "discriminant function is similar to a regression equation with a categorical dependent variable" (p.799). This type of analysis 
answers two major questions. It ascertains whether or not the set of independent variables is good in distinguishing between two categories. Secondly, it can determine which independent variables account for statistically significant differences between the groups (Kerlinger \& Lee).

The purpose of using this function analysis was to predict group membership. In this study, discriminant analysis using multiple regression was used to determine which independent variables, attitude, subjective norm, and perceived behavioral control, accounted for the differences in the group (teachers) that have actually referred suspected eating disordered students to counseling and the group (teachers) that have not ever referred suspected eating disordered students to counseling.

Hypothesis 3 examined if there was a proportion of unique variance that each of the three constructs, attitude, subjective norms, and perceived behavioral control, contributed to predicting teacher intention to refer. Testing of this hypothesis was completed as a component of multiple regression analysis for hypothesis one.

\section{Summary}

A non-experimental design was used to explore middle school teachers' attitudes, subjective norm, perceived behavioral control and their behavioral intention and behavior regarding referring students suspected of an ED. A previously developed instrument was adapted and tested for reliability among the target population. Quality enhancement techniques were employed. The data met the assumptions necessary for parametric testing, therefore three hypotheses were tested; one and three by means of multiple regression and the second by means of discriminant analysis. The results of these 
analyses were used to report the efficacy of the TPB in predicting the behavior among the sample.

\section{Overview of Chapter 4}

Chapter 4 presents the results of hypotheses testing that used multiple regression and discriminant analysis. Data from descriptive statistics is provided. In addition, commentaries from some middles school teachers are presented with reference to their actual behavior of referring and not referring suspected students of ED to professional counseling. 


\section{CHAPTER IV}

\section{RESULTS}

The purpose of this study was to examine selected relationships of the theoretical constructs of the TPB, attitude, subjective norm, and perceived behavioral control, among middle school teachers who suspected students of having AN and BN and the actual behavior of these teachers regarding referral for counseling and those teachers who reported not having made such a referral. Descriptive techniques were employed to describe the sample and the scores obtained on the scales used to operationalize the research variables. The composite scores on the scales were all converted to relative scores by dividing the composite score by the number of items on the scale to maintain the 1-7 meter of the scales and allow for logical comparisons. The scores obtained on the scales used to measure the research variables were further subjected to tests of reliability as internal consistency by means of Cronbach's alpha. Statistical applications for hypothesis testing included multiple regression and discriminant function analysis.

In total, 328 questionnaires were actually distributed to middle school teachers in five public middle schools in Broward County, Florida, over a period of approximately 10 weeks. Two hundred and ten questionnaires were to be distributed to make sure 105 usable questionnaires would be collected, however since the return rate was very low at some schools the researcher distributed a total of 328 questionnaires. Of the 328 questionnaires, 115 were returned and $114(34.7 \%)$ were adequately completed and were used for data analyses. One questionnaire was eliminated in the data analysis because of incomplete data. There was a 35\% response rate. 


\section{Descriptives}

\section{Description of the Sample}

The participants were predominantly female, $(n=93,81.6 \%)$ with only 21 $(18.4 \%)$ male. Most of the participants $(n=87,76.3 \%)$ in the sample had never suspected that a student in their class had an eating disorder but $26(26 \%)$ had such suspicions; one participant did not respond (.9\%). Ninety two (80.7\%) had never referred a student suspected of having an eating disorder for counseling but 21(18.4\%) had made such a referral; one participant did not respond (.9\%). Details of the demographics are presented in Table 1. 
Table 1

Demographic Characteristics of Participants $(N=114)$

$\begin{array}{lll}\text { Characteristic } & n & \%\end{array}$

Age at time of survey (years)

$$
\begin{aligned}
& 20-29 \\
& 30-39 \\
& 40-49 \\
& 50-59 \\
& 60 \text { or more } \\
& \text { No response }
\end{aligned}
$$

27.2

21.1

28.1

32

7

6.1

1

.9

Ethnicity/Race

White

African American

15

13.2

Hispanic

10

8.9

Asian

1

African Caribbean

3

.9

Other

2.6

No response

9

7.9

2

1.8

Highest education level completed
Bachelor's of Arts
Bachelor's of Science
Master's of Education
Master's of Arts in Teaching
Doctor of Education (Ed. D)
Other
No response

25

21.9

30

42

1

26.3

36.8

1

.9

14

.9

1

12.3 


\section{Responses to the Variable Measures}

Descriptive statistics were obtained for the four research variables. Table 2 demonstrates the value of each individual mean, standard deviation and range. The variable intent was the highest, followed by subjective norm (peer influence and individual's motivation to comply with those impressions), attitude (beliefs) and perceived behavior control (degree to which they have control over performing a behavior). Based on the scale from (1) extremely low, (2) quite low, (3) slightly low, (4) neither low nor high, (5) slightly high, (6) quite high, and (7) extremely high, the mean of all of the variables ranged from slightly high to quite high. Table 2 provides a summary of these values.

Table 2

Descriptive Statistics for the Scores of the Research Variables $(N=113)$

\begin{tabular}{lcccc}
\hline \multicolumn{1}{c}{ Variable } & $M$ & $S D$ & range & $n$ \\
& & & & \\
\hline $\begin{array}{l}\text { Attitude } \\
\text { Subjective norm }\end{array}$ & 4.78 & 1.18 & $1.73-6.82$ & 112 \\
$\begin{array}{l}\text { Perceived behavioral } \\
\text { control }\end{array}$ & 5.96 & 1.05 & $2.00-7.00$ & 113 \\
Intent & 4.72 & .87 & $1.82-6.45$ & 111 \\
& 6.01 & 1.40 & $1.00-7.00$ & \\
\hline
\end{tabular}




\section{Reliability Testing}

The scales used to measure the research variables were evaluated for reliability as internal consistency by means of Cronbach's alpha. The criterion to identify poorly functioning items was a measurement below .30 for corrected item-total correlation (Nunnally \& Bernstein, 1994).

The 11 items on the scale for Attitude achieved an alpha of $.85(n=112)$. Two items, numbers $10(.24)$ and $11(-.04)$, fell below the .30 criterion and indicate that these items were not correlated with the other items on the scale. If these items had been deleted, the overall alpha would have increased to .88 . However, as .85 was considered an acceptable overall alpha value, these items were retained in the analysis.

The nine items on the scale for Subjective Norm achieved an alpha of .91 $(n=$ 113). One item, number 20 (.23), fell below the .30 criterion but, again, the overall alpha was quite acceptable and the item was retained.

The 11 items on the scale for Perceived Behavioral Control achieved an overall alpha of $.72(n=113)$. Two items, numbers $26(-.23)$ and $72(-.25)$ fell below the .30

mark. Deletion of these items would have increased the overall alpha to .78 so these two items were retained in the analyses.

The scale for Behavioral Intent contained three items and achieved an overall alpha of $.95(n=111)$. No item on this scale fell below .88. While all overall alphas were above the traditional acceptable value of .70, all items that fell below the .30 corrected item-total correlation should be examined and possibly reworded.

\section{Hypothesis Testing}

Prior to hypothesis testing, scores for the dependent variable, Behavioral Intent, 
were examined for outliers and normal distribution. The values of skewness (-1.58) indicated that the scores tend to pile up on the right of the distribution. The value of kurtosis (2.13) indicated that the distribution was rather pointy in distribution; and the further the value from zero, the more likely the data were not normally distributed. Examination of the histogram clearly indicated that the scores were not normally distributed with a negative skew. This observation was supported by the significant Kolmogorov-Smirnov statistic $(K S=.27, p<.001)$.

Boxplot identified only two extreme scores of three representing outlying values falling three standard deviations (SD) below the mean. While elimination of these outlying scores was considered, they were viewed as legitimate components of the data set and were left in the study. No attempt was made to transform these scores to achieve a more favorable distribution. The limitations that were imposed by this non-normal distribution of scores were acknowledged; however, parametric testing methods with large sample sizes are considered to be robust, and the results are trustworthy even in the presence of non-normal distributions (Hill \& Lewicki, 2006). Therefore, hypotheses testing proceeded.

\section{Hypothesis 1}

Hypothesis 1 considered if there was a statistically unique and combined relationships among the variables to determine if attitude, subjective norm, and perceived behavior control were predictive of behavioral intent which is presented in Table 3 . Examination of the correlation table and collinearity statistics between the predictor variables, tolerance $(<.1)$ and variance inflation factor $(\mathrm{VIF})(<10.0)$, indicated that multicollinearity was not a concern (Field, 2005). The findings revealed that there was a 
statistically significant positive relationship with all the constructs, attitude, subjective norm and perceived behavioral control and the behavioral intention of middle school teachers to refer students suspected of ED to professional counseling. Subjective norm (peer influence, what others thought about his/her performance of referring, combined with the individual's motivation to comply with those impressions) had the highest influence on the teachers' intent to make a referral.

Table 3

Means (M), Standard Deviations(SD) and Intercorrelations for the Outcome Criterion of Behavioral Intent(BI) and the Predictor Variables of Attitude(1), Subjective Norm(2), and Perceived Behavioral Control(3)

\begin{tabular}{lccccc}
\hline \multicolumn{1}{c}{ Variable } & $M$ & $S D$ & 1 & 2 & 3 \\
\hline $\begin{array}{l}\text { Behavioral Intent } \\
\text { Predictor variable }\end{array}$ & 6.07 & 1.30 & .34 & .59 & .43 \\
$\begin{array}{l}\text { Attitude } \\
\begin{array}{l}\text { Subjective norm } \\
\text { Perceived behavioral } \\
\text { control }\end{array}\end{array}$ & 4.78 & 1.19 & -- & .33 & .34 \\
& 5.95 & 1.05 & & -- & .35 \\
\hline
\end{tabular}

Note. Constructs are represented by numbers: Attitude (1), Subjective norm (2) and Perceived behavioral control (3)

\section{Hypothesis 2}

Of the 114 participants, $26(22.8 \%)$ reported that they had previously suspected that a student had an eating disorder. Of these 26, $21(80.8 \%)$ had made a referral for counseling while five (19.2\%) had not made such a referral.

Hypothesis 2 considered if there were statistically significant differences in the mean scores for behavioral intent between the middle school teachers that report having ever referred a student suspected of having an ED for counseling or not having made 
such a referral. Group membership was utilized to examine if the variables of attitude, subjective norm, perceived behavioral control and/or intent were predictors of having referred or not having made such a referral. This hypothesis was tested by means of discriminant function analysis with all predictors entered together.

As the outcome variable was dichotomous, as expected, one factor was revealed and explained $100 \%$ of the variance, canonical $R^{2}=.743$. In combination, these discriminant functions significantly differentiated the groups, $\Lambda=.45, \mathrm{X}^{2}=16.84$ (4), $p=$ .002. The correlations between the outcome and the discriminant functions revealed that Behavioral Intent loaded highly $(r=.77)$, Perceived Behavioral Control $(r=.54)$ and Subjective Norm $(r=.44)$ loaded in the medium range but Attitude $(r=.07)$ did not. This was further evidenced by the standardized canonical discriminant function coefficients whereby Perceived Behavioral Control (.76) and Behavioral Intent (1.03) were the only predictors contributing to the model with Behavioral Intent being the strongest predictor. Attitude (-.37) and Subjective Norm (-.40) were not predictors.

The findings supported the hypothesis that there was statistically significant difference in mean scores for those that reported having ever referred and those not having made such a referral. While the results of this analysis may be intriguing, they must be viewed with caution. The sample size was very small and the groups were grossly unequal. Post hoc analysis for power for the discriminant function analysis was computed using the criteria of medium effect, alpha $=.05$, with four measures and two groups, and a sample size of 26 , power $=.48$ ). Additional information related to the analysis is provided in Table 4 and 5. 
Table 4

Means and Standard Deviations of Predictor Variables as a Function of the Outcome Variable of Ever Having Referred and Not Having Ever Referred a Student for Counseling for an Eating Disorder

\begin{tabular}{|c|c|c|c|c|}
\hline \multirow[b]{2}{*}{ Predictor Variable } & \multicolumn{2}{|c|}{$\begin{array}{l}\text { Have } \\
\text { referred }\end{array}$} & \multicolumn{2}{|c|}{$\begin{array}{l}\text { Have not } \\
\text { referred }\end{array}$} \\
\hline & $M$ & $S D$ & $M$ & $S D$ \\
\hline Attitude & 5.09 & 1.10 & 4.89 & 1.19 \\
\hline Subjective norm & 6.22 & .86 & 5.09 & 1.95 \\
\hline Perceived behavioral & & & & \\
\hline Control & $5.15_{\mathrm{a}}$ & .77 & $4.35 \mathrm{a}$ & .29 \\
\hline Intent & $6.70_{b}$ & .90 & $5.60_{b}$ & 1.34 \\
\hline
\end{tabular}

Note. Means with the same subscript differ significantly at $p<.05$.

Table 5

Classification Analysis for Ever Having Referred and Not Having Ever Referred Predicted group membership

\begin{tabular}{|c|c|c|c|c|c|}
\hline \multirow[b]{2}{*}{ Actual group membership } & \multirow[b]{2}{*}{$n$} & \multicolumn{2}{|c|}{ Have not referred } & \multicolumn{2}{|c|}{ Have referred } \\
\hline & & $n$ & $\%$ & $n$ & $\%$ \\
\hline Have not referred & 5 & 4 & 80.0 & 1 & 20.0 \\
\hline Have referred & 20 & 3 & 15.0 & 17 & 85.0 \\
\hline
\end{tabular}

Note. Overall $\%$ of correctly classified cases $=84.0 \%$. Missing 1 discriminating variable 


\section{Hypothesis 3}

Hypothesis 3 considered what proportion of unique variance each of the three constructs: attitude, subjective norm, and perceived behavioral control, contributed to predicting teacher behavioral intention to refer. The results of the multiple regression analysis indicated that the combination of the variables accounted for $41.2 \%\left(R^{2}=.412\right.$, $\left.\operatorname{Adj} R^{2}=.395\right)$ of the variance in the model and the model was significant, $F(3,103)=$ 24.03, $p=.001$. However, examination of the beta weights shows that attitude was not a statistically significant unique predictor. Subjective norm and perceived behavioral control were the only variables that were statistically significant unique predictors of Behavioral Intent.

Post hoc analysis for power was computed for multiple regression using the criteria of medium effect, alpha $=.05$, with three predictors, with a sample of 114 , power $=.94$. Therefore, the results may be viewed with confidence and the hypothesis was confirmed. The summary of the regression analysis is provided in Table 6 .

Table 6

Regression Analysis Summary for Variables Predicting Behavioral Intent

\begin{tabular}{|c|c|c|c|c|c|}
\hline Variable & $B$ & $S E B$ & $\beta$ & $t$ & $p$ \\
\hline Attitude & .033 & .025 & .110 & 1.33 & .186 \\
\hline Subjective norm & .196 & .034 & .474 & 5.717 & .000 \\
\hline $\begin{array}{l}\text { Perceived behavioral } \\
\text { control }\end{array}$ & .092 & .034 & .223 & 2.668 & .009 \\
\hline
\end{tabular}

Note. $R^{2}=.412(N=107, p=.00)$. 


\section{Qualitative information}

Comments from the teachers that suspected and referred. In addition to the statistical data results, one question in the questionnaire asked the participants to comment on the factors that may have facilitated their referral or inhibited their referral. Most of the comments did not identify the factors that facilitated or inhibited their referrals; however they did offer an insight regarding how the teachers' perceived the students that were in their classes. Out of the 21 teachers' commentaries, there were three predominant themes: "rapid weight loss," "did not eat lunch," and "physical signs." Rapid weight loss. The first predominant theme was "rapid weight loss." The following comments were provided by 9 teachers:

"The young lady in my class began to lose weight rapidly-It concerned me so I spoke with her, but she didn't want to talk about it. I spoke to a close friend who told me that she was depressed about her parents' divorce. I then referred her to guidance. I don't remember specifically what happened-Whether she was given help or guidance, but she has always stayed in my memory."

"Student experienced extreme weight loss in short time-Student overdoing exercise-to the extreme-Did not eat during lunch-Friends were extremely concernedOften ill-requested pass to clinic or restroom."

"Student wasn't eating was losing weight rapidly. Referred student to guidance and was taken from there."

"She lost a lot of weight-6th grade student refused to take candy or eat any treats. Her mother forced her to exercise/go running. My school guidance counselor was a 
wonderful support. Note: I taught a class of 15 students [ergo] the class size affects how well a teacher gets to know the students."

"Anorexia-student lost tons of weight way too fast-we had many conversations about it-I referred the matter to Guidance-we made a conference call home alerting student later went to treatment facility."

"Female 7th grader lost a lot of weight very quickly. She was starving herself and then was light headed, dizzy, etc. I referred her to guidance. She is healthy and in high school now."

"Rapid [wait] loss -apathy-loss in motivation."

"One student of mine lost weight rapidly. I knew he was eating and cared for at home, but knew there was a problem. I continued to ask the parent to make a [dr's appt], out of concern, but when they did not, I referred to Guidance. This forced the parent to go to the doctor eventually [\&] I feel I saved the child's life. He had juvenile diabetes [\&] was in shock in the hospital. It was caught just in time."

"Suspected a student. Turns out he had full blown diabetes and was hospitalized for a week. Parents (DAD) were obviously very thankful. ID Factors- Loss of weight, very quiet, lethargic."

Two of the 9 teachers that did notice "rapid weight loss" and referred the students because they suspected they had an ED, commented that their referrals lead to the diagnosis of another medical condition, juvenile diabetes. Even though the children did not have an ED, it appeared the two teachers' astute observations and referrals resulted in helping save the children from harm. 
Did not eat lunch. The second predominant theme was: "did not eat lunch." The following comments are those of the 4 teachers:

"She would not eat at lunch or at class "gatherings." A friend of hers told me she had a "habit of doing this."

"It has been a while but in the past I have referred students who stopped eating lunch. I referred [then] to or department's family counselor. I would do it again if I suspected a student of an eating disorder."

"This student would never eat when other student would eat or would eat and then throw up. was a cheerleader, a straight "A" student, over-achiever type, very thin, exercised a lot. I did refer her to peer counseling teacher [\&] then to school psychologist."

"The student ate very little, played [w/his] food [\&] appeared to be losing weight."

Physical signs. The last predominant theme was: "physical signs." These are the 2 teachers' comments:

"Socially withdrawn-opting to eat lunch, at home (actually avoiding $7 \mathrm{hrs}$ of eating)-lack of shine in hair, loose clothes, bones protruding, always tired /lethargic."

"Most often I have been able to detect eating disorders in female students who were in my classes in 6 th grade, but I continue to see them as they get older. The physical changes are what I usually first notice."

Comments from the teachers that did not suspect and did not refer. The 7 teachers' who commented that they never suspected an ED and had not referred any 
student for counseling wrote a few attention-grabbing themes. The most predominant theme was "never suspected." The following are the 7 teachers comments:

"I haven't suspected a student of having an eating disorder."

"I have not seen/had a student with an eating disorder, that I've suspected."

"I haven't ever suspected a child of having an eating disorder. I'm not sure of the signs to look for."

"I have not in my teaching experience thus far suspected a student of having an [eat] disorder. I have had students who have had family members with eating disorder but not with their own."

"Nothing inhibits me from notifying a school counselor should I suspect a student of having an eating disorder."

"Some kids are smaller than others."

"Never thought it was necessary. Not sure who to tell."

Comments from the teachers that suspected but did not refer. The 2 teachers that suspected that a student may have had an ED but did not refer the students for counseling added some significant comments to this study.

"We have so many students who don't eat lunch. First, I see if they look healthy then I call parents. The warning signs to me are especially the girls when they comment on their weight or are embarrassed to eat in front of their peers."

"I believe it is a family issue- obesity is a result of an eating disorder-mom [\&/or] dad is obese too- Anorexia or Bulimia is rare here- I wouldn't hesitate to submit a request for counseling." 
The teachers comments provided a valuable insight into what they observed about the students in their classroom. Some teachers referred and others did not refer students based on their suspicions that the student had an eating disorder where others did not even suspect that students could be dealing with an eating disorder. A lack of knowledge about eating disorders was expressed by some teachers. Since the statistical findings in this study found subjective norm (peer support) and perceived behavioral control (confidence and resources) as strong predictors one might get the impression if the teachers had the knowledge about EDs, had positive peer support and felt empowered they might take the initiative to refer.

\section{Summary of Chapter Four}

A sample of sufficient size to detect a medium effect between the variables considered in hypothesis 1 and hypothesis 3 was recruited from the target population of middle school teachers. The sample that qualified for inclusion in hypothesis 2 fell short of the number that was expected and while analysis of the data was carried out, results must be viewed with caution.

Data were used to both describe the sample and the variables. The scales used to measure the variables were shown to have appropriate reliability as internal consistency despite that some of the individual items performed poorly. The distribution of the scores for the dependent variable, intent, was found to be non-normally distributed; however, authority supported the use of parametric testing as it is considered robust even in the light of non-normal distribution. Only two outlying scores were detected on the dependent variable and these were left unchanged. 
Multiple regression analysis revealed that subjective norm and perceived behavioral control were predictive of intent but attitude was not. Discriminant function analysis supported that both intent and perceived behavioral control were predictive of group membership, either having referred a student suspected of having an eating disorder for counseling or not having made such a referral, but attitude and subjective norm were not predictive of group membership.

The written comments from some of the teacher participants added insight regarding the teachers' observations of their students. Some of the commentaries that emerged provided valuable information relating to the actual behavior of some teachers in the study. Indeed, the "voices" of those teachers that suspected students had an ED and referred as well as those who suspected students had an ED and did not refer added to the findings of this study. In addition, those teachers that did not suspect their students had an ED might be a sign middle school teachers need to have more knowledge about these teenage onset diseases.

\section{Overview of Chapter 5}

Chapter 4 provided the results of the study. Chapter 5 presents the summary, discussion of the limitations and implications of the study. Recommendations for future research are addressed along with the conclusions of the study. 


\section{CHAPTER V}

\section{DISCUSSION}

The purpose of this study was to examine (a) the relationships of the theoretical constructs, attitude, subjective norm, and perceived behavioral control of the TPB as predictors of behavioral intention (Ajzen \& Fishbein, 1980) when middle school teachers identify and refer students suspected of AN and BN for professional help; and (b) the actual behavior of middle school teachers that reported having ever referred a student suspected of having AN and $\mathrm{BN}$ as well as those teachers who reported not having made such a referral.

Five middle schools in Broward County, Florida, were used to distribute the 328 questionnaires. One hundred fifteen questionnaires were collected and 1 questionnaire was eliminated due to incomplete data. The data analysis was completed using Statistical Package for the Social Sciences (SPSS) for Windows v. 19.0 (SPSS, 2007).

This chapter will discuss the main findings of the data analysis, prior research, implications, and limitations along with recommendations for future research. Three hypotheses directed this study: (a) Is there a statistically significant relationship, uniquely and as a linear composite, between the theoretical constructs, attitude, subjective norms, perceived behavioral control and the behavioral intent of middle school teachers to refer students suspected of AN and BN for professional counseling? (b) Is there a statistically significant difference in the mean scores for behavioral intent between the middle school teachers that report having ever referred a student suspected of having AN and BN and those middle school teachers that report not having made such a referral? and (c) What is 
the proportion of unique variance each of the three constructs, attitude, subjective norms, and behavioral control, contributes to predicting teachers' intention to refer?

\section{Results}

The findings pertaining to hypothesis 1 revealed there was a statistically significant positive relationship with all the constructs, attitude, subjective norm and perceived behavioral control and the intention of middle school teachers to refer students suspected of ED to professional counseling. The outcome criterion of intent and the predictor variables of attitude (positive or negative feeling about performing a behavior), subjective norm (what others thought about his/her performance of referring, combined with the individual's motivation to comply with those impressions) and perceived behavioral control (power, confidence, ease of performing a behavior) provided evidence that subjective norm had the highest influence on teachers' intent to refer. According to the findings, guidance counselors, administrators, people who were important to the participants, and those people whose opinions they valued, strongly influenced the middle school teachers' intent to refer suspected students.

Martin, Kulinna, Eklund, and Reed (2001) used the TPB model along with the theory of reasoned action and self-efficacy, to focus on the prediction of teachers' intention to teach physically active, physical education classes, that is spending at least $50 \%$ of class time of moderate to vigorous physical activity, supported the findings of this current study. Subjective norm was the most predictive construct along with attitude to strongly endorse highly active classes. Their findings, however, did not corroborate with the result of this study that perceived behavioral control played a positive role. In fact, their results revealed that perceived behavioral control and self-efficacy failed to 
contribute to the prediction of teachers' intention to endorse the physically active physical education classes.

The findings of hypothesis 2 revealed that the correlations between the outcome and the discriminant functions showed that behavioral intent was in the high range, perceived behavioral control and subjective norm were in the medium range but attitude did not fall in either of those ranges since it was the lowest. The results found that 21 of the 26 teachers that suspected students of having AN or BN and referred them for professional counseling were highly intent on making a referral. The results implied that the participants felt confident and at ease to refer students (perceived behavioral control) and were influenced by their peers (subjective norm). Conversely, attitude (behavioral beliefs) did not make a significant contribution when predicting referrals. The results suggested that even if a teacher had a positive attitude about a referral, but did not feel confident and well supported, he/she might not refer a student to professional counseling.

The findings of hypothesis 3 revealed that subjective norm was the most statistically significant unique predictor of the middle school teachers' intention to refer a student suspected of AN or BN to professional counseling. Perceived behavioral control construct was a statistically significant predictor as well. Attitude was not a statistically significant predictor.

The results of the prior research studies (Burak, 1994; Burak, 2002; Lumpe, Haney, \& Czerniak, 1998; Zint, 2002) in the literature search corroborated with the findings of this study that perceived behavioral control and subjective norm played a significant role in predicting the intention of the teachers. However, their findings 
showed that the most predominant predictor was perceived behavioral control not subjective norm.

Burak's (1994) study revealed that both perceived behavioral control and subjective norm contributed to teachers' behavior to teach HIV/AIDS. The construct of perceived behavioral control contributed most significantly regarding the teachers' intention to teach about HIV/AIDS. Another study of Burak (2002) examined elementary teachers' intentions to teach health education utilizing the TPB. The results revealed that variables of the TPB explained $52.3 \%$ of the variance in teachers' intentions and revealed that perceived behavioral control made the most substantial contribution to predicting teachers' intention to teach health education.

The Lumpe, Haney, and Czerniak (1998) study which examined the factors that influenced K-12th graders teachers' intention to use cooperative learning in their science classes revealed that subjective norm and perceived behavioral control were significant predictors of the teachers' behavior. Again their results showed that perceived behavioral control had the greatest influence on a teacher's intent to employ cooperative learning.

Utilizing the TPB, Zint (2002) examined science teachers' intention to incorporate environmental risk education in the classroom utilizing the TPB. The overall results indicated that perceived behavioral control was the most significant predictor along with subjective norm when investigating the intention of science teachers to incorporate this topic in their teaching.

In summary, the results of the current study revealed that subjective norm was the most significant and predominant predictor of the middle school teachers' intention to refer students suspected of AN and/or BN to counseling. The perceived behavioral 
control construct also played a statistically significant role. The teachers' attitude however, was not a statistically significant predictor. Out of all the 114 participants in the study, 21 teachers actually did make the referral for their suspected students to get professional counseling. In this study, the middle school teachers' perceptions suggested that they were of the opinion that they were well supported by their peers and felt confident that they had the power, conviction and resources to make those critical referrals.

\section{Limitations of the Study}

Regardless of the strengths of this study there are a few limitations. One of the limitations is that this is the first study to use TPB to research the three constructs as predictors of behavioral intention of middle school teachers to refer students suspected of $\mathrm{AN}$ or $\mathrm{BN}$ and to examine the actual behavior of those teachers who have reported ever referring a student suspected of having $\mathrm{AN}$ or $\mathrm{BN}$ as well as those teachers that report not having made such a referral.

Another limitation was the use of a convenience sample. In order to achieve a robust sample, middle school teachers were selected from Broward County, Florida, given that the group of participants were accessible, expedient and convenient (MacMillan \& Schumacher, 2001; Vogt, 2005). The selected middle schools were familiar to the researcher, and some schools were selected based on the researcher's association with teachers and other persons that could help with recruiting teachers. This type of sample is considered a limitation since there is no precise way of generalizing to other middle school teachers. 
The teachers' lack of knowledge about the early signs of AN or BN could be considered a limitation. Out of 114 teachers only 26 teachers suspected a student had an eating disorder and out of the 26 only 21 actually referred. In fact, 3 teachers wrote comments suggesting that they did not have the knowledge to refer. They relayed that they have not ever suspected or had a child with an eating disorder in their classes; they were not sure of the signs to look for; and that they were not qualified to make medical assumptions.

Another limitation was the instrumentation used in the study. Even though the population was similar (teachers) and the instrument was reviewed by an expert panel of educators, the use of an adapted instrument in this study could be considered a limitation.

An additional limitation was the self-reported questionnaire. A cover letter explaining the purpose of the study and instructions was attached to the questionnaire. Even though instructions were provided, it was possible there was a lack of understanding, concern of truthfulness, and biases that may have affected their responses to the questions.

The timing of the questionnaire distribution could be considered a limitation. Obtaining permission to distribute the questionnaires required Broward County IRB approval, even though the study had IRB approval from Florida International University. The process and requirements took over 21 weeks. According to a few office managers, distributing the questionnaires a few months prior to Florida Comprehensive Assessment Test (FCAT) testing, was problematic when trying to get teachers to volunteer.

The approved schools were contacted and the office manager, who makes appointments for the principals, sometimes denied the request. Determination and 
fortitude did not always help with accessing some schools. As a result of office managers denying a request for an appointment with the principal, the researcher had to submit another request at the Broward School Board for permission to utilize additional schools for the study. The approval process took additional weeks and the delay brought the distribution of questionnaires closer to the date of FCAT testing which may have limited the number of volunteers.

Teachers' beliefs that it was not their responsibility to refer students for medical issues might have been a limitation. Traditionally, eating disorders were primarily handled by the school nurses, school counselors, school psychologists or school administrators. However, today the classroom teachers are expected to refer students for counseling (Barnes et al., 2004) yet they may not believe it is their responsibility. The participation in this current study was voluntary; however, a few teachers believed they needed to express themselves in writing by commenting that it was not part of their responsibility to refer students. As an example, one teacher wrote in large black script all over the pages of the questionnaire that she was a non medical professional and was not qualified to make a medical assumption.

\section{Implications of the Study}

In view of the fact that eating disorders are now being identified in younger children, teachers' engagement in prevention efforts of suspected ED students seems imperative (Smolak et al, 2001). Scholars like Ransley (1999, p. 38) indicate that "The teacher should try to encourage the pupil to obtain some professional support from a school nurse, counselor or general practitioner." These diseases, many experts agree, can lead to a negative impact on students' academic growth, nutrition, and even death 
(Claude-Pierre,1997; Manley et al., 2000; Romeo, 1996). Therefore, because teachers are most often involved with these students five days a week, every week of a school year, the teachers' referrals for such physical conditions of students might save lives.

The following implications from the current study will focus on the means to enhance middle school education, middle school practice and future research to help in the early prevention process.

\section{Implications for Middle School Education}

According to Natenshon, (1996), more eating disorder education is needed for those working in schools. Out of 114 completed questionnaires, only 26 middle school teachers reported they suspected students had an ED and only 21 actually referred them to counseling. This finding leads to many unanswered questions. Why so few referrals? Could the answer be there were no students demonstrating signs of AN and/or BN in the classrooms? Or could it be that teachers lack education and knowledge regarding AN and/or BN? Or could it be some teachers feel eating disorders are medical conditions and not a part of their teaching responsibility? Or could it be that teachers did not feel supported by other teachers and administration? Or could it be that teachers lack knowledge about eating disorders, lack knowledge about the process of referrals or lack the resources to make the referrals?

In this research study, seven teachers commented that they never had a student in their classroom that demonstrated signs of AN and/or BN. Perhaps they lacked the knowledge to even suspect. Actually three teachers commented that they did lack knowledge about $\mathrm{AN}$ and/or BN and therefore never ever suspected they had a child with an eating disorder in their classes. 
Implementing educational professional development programs might be a valuable step to increase teachers' knowledge regarding AN and/or BN (Yager \& O’Dea, 2008). Based on the findings of the Zint (2002), administrators, peers, students, parents, and other individuals believed professional development interventions should be implemented. Having a solid foundation about the diseases would help to empower middle school teachers. According to Smolak, Harris, Levine and Shisslak ( 2001), teachers want to know more so they are better prepared with knowledge and skills to refer suspected students of ED to professional counselors. Some teachers clearly feel they need more information concerning signs and symptoms for eating disorders. Empowering the teachers with knowledge might give them the confidence that they are personally and professionally capable of referring students (Ballone \& Czerniak, 2001; Yager \& O'Dea, 2005).

Another suggestion for middle school education is to implement eating disorder information in undergraduate education curricula. According to the findings in this study, perceived control (confidence and resources) as well as subjective norm (peer support) were significant predictors of teachers' intent to refer; therefore informing undergraduate students of signs of AN and BN, referral resources, and stressing the importance of peer support in their educational program, they should be better informed to refer students. Adding these areas would enhance existing undergraduate curricula. Ballone and Czerniak (2001); Neumark-Sztainer, Story, and Coller (1999); and Smolak et al., (2001) studies support the idea that there is a need for necessary curricular reform. Their findings revealed that there was an interest by teachers to know signs and symptoms of EDs and to learn the prevention tools. Implementing these changes may 
possibly help empower beginning teachers to feel more confident to identify suspected students and make the referral.

\section{Implications for Middle School Practice}

The results of this study have indications for middle school teaching practice. Since classroom teachers are more aware of pupils with AN and BN, even more so than the school nurse, they can be instrumental in early interventions thus preventing complex problems (Rees \& Clark-Stone,2006). If teachers are provided with staff development programs or workshops, focusing on therapeutic communication skills and how to have constructive interactions with students suspected of $\mathrm{AN}$ and/or $\mathrm{BN}$, perhaps more teachers would feel comfortable making referrals a part of their daily teaching practice (Piran, 2004a). According to Layton (2003) teachers can act as a valuable link between a suspected ED student, school resource person and the professional counselor.

Perhaps a school-wide project could be implemented to address the issue of eating disorders, anorexia nervosa and bulimia nervosa, as well as other health issues. This type of undertaking could reach students, teachers, coaches, and staff. According to Griffin and Harris (1996) and Layton (2003), coaches demonstrated inability to detect EDs or if they did identify students they felt it was inappropriate to intervene. Instituting a project of this type would help teachers, students, administrators and staff with health promotion and illness prevention.

\section{Implications for Research}

This may be the first study to examine the variables of attitude, subjective norm, and perceived behavioral control of the TPB as predictors of behavioral intention when middle school teachers identify and refer students suspected of AN and BN for 
professional help and therefore more research is needed. This study may also be the first to examine the actual behavior of middle school teachers that report having ever referred a student suspected of having $\mathrm{AN}$ and $\mathrm{BN}$ and those teachers who report not having made such a referral. Hopefully, the results of this study will encourage future researchers to replicate the study.

Another implication for research would be to distribute the findings of this study to the national population of middle school teachers through professional meetings and professional associations. Sharing the results of this study will possibly encourage more research on this topic, add to the literature, enlighten middle school teachers along with other teachers, administrators, guidance counselors, school psychologists and those in other disciplines that early interventions with EDs is crucial.

\section{Recommendations for Future Research}

Replicating this study would help to validate the theory of TPB. The inclusion of the demographics of age, ethnicity, gender, culture, educational preparation, and the teachers' knowledge of eating disorders in the analysis would help to expand the findings of future studies.

Since this study focused on middle school teachers in Broward County, Florida, and can not be generalized to other counties, replicating the study in other counties or in other states might add to this study's findings.

Another suggestion for further research is to study this topic utilizing another research approach. Despite the theory of planned behavior's important quantitative contributions of examining relationships between attitudes and behaviors, another research approach would add to the explanation of behavior and research findings 
(Peterson \& Bredow, 2004). Approaching this research from a qualitative perspective may well offer a clearer insight in relation to the teachers' needs, concerns and obstacles that hinder them from referring students suspected of $\mathrm{AN}$ and /or BN to counseling. According to Smolak, Harris, Levine and Shisslak (2001), teachers' voices must be heard regarding their needs to help in eating disorder prevention efforts. Teachers ought to be engaged and listening to them may be the key. Utilizing a qualitative approach may well provide a better understanding of teachers' thoughts, needs and behavior which might add to the findings of this study.

Additional research, focusing on diversity from the teachers' perspective about eating disorders and body image, is recommended as it might yield noteworthy data. Teachers' responses on questionnaires may well be based on their own cultural bias. For example, a teacher who does not feel thinness is a problem but an asset may not even suspect that a student has a problem with anorexia nervosa. In the United States, among African Americans where anorexia nervosa is less frequently seen, teachers may not have been exposed to the condition and as a result might not recognize the signs or symptoms Andreasen and Black, 2006 ( as cited in Videbeck, 2011).

\section{Conclusions}

The current study examined (a) the relationships of the theoretical constructs: attitude, subjective norm, and perceived behavioral control of TPB as predictors of behavioral intention (Ajzen and Fishbein, 1980) when middle school teachers identify and refer students suspected of AN and BN for professional help; and (b) the actual behavior of middle school teachers that reported having ever referred a student, and those teachers that reported not having made such a referral. The findings indicated that 
perceived behavioral control and subjective norm played a statistically significant role as predictors of the middle school teachers' intention to refer students for counseling. Since these constructs are positive predictors, they seem vitally important as tools to empower and support teachers in their prevention efforts regarding early referrals (Smolak et al., 2001).

Two middle school teachers, participating in this study, demonstrated just how crucial it was to refer early. The two teachers, through their testimonies, suggested that they may have "saved the lives" of the students because they suspected the students had an eating disorder and referred them for professional help. One teacher's account, "...I feel I saved the child's life...it was caught just in time," showed how essential referrals can be. Even though the student's symptoms turned out to be diabetes, the teacher's referral indicated the value of an early intervention. The other teacher, who made that important referral, found out later that because of her intervention, that the child had "full blown diabetes: was discovered "and was hospitalized for a week."

Given the fact that eating disorders negatively impact students' academic growth, nutrition and sometimes can cause death, the results of the present study may inspire teachers to become involved in early intervention referrals; motivate administrators to implement professional development programs or workshops that can educate teachers about $\mathrm{AN}$ and $\mathrm{BN}$; and rouse the interest of educators to address the topic of eating disorders, the importance of referral resources, and value of teacher support in their curriculum (Claude-Pierre, 1997; Manley et al., 2000; Romeo, 1996). 


\section{LIST OF REFERENCES}

Ajzen, I. (1991). The theory of planned behavior. Organizational Behavior and Human Decisions Processes, 50, 179-211.

Ajzen, I. (2001a). Constructing a TpB questionnaire: Conceptual and methodological considerations. Retrieved from http: //www.unibielefeld.de/ikg/zick/ajzen $\% 20$ construction $\% 20 \mathrm{a} \% 20 \mathrm{tpb} \% 20$ questionnaire.pdf

Ajzen, I. (2001b). Nature and operation of attitudes. Annual Review Psychology, 52, $27-$ 58.

Ajzen, I. (2002). Perceived behavioral control, self-efficacy, locus of control, and the theory of planned behavior. Journal of Applied Social Psychology, 32(1), 1-20.

Ajzen, I. (2004). Icek Ajzen Homepage. Retrieved from: http://www-unix.oit.umass.edu/aizen/

Ajzen, I., \& Fishbein, M. (1980). Understanding attitudes and predicting social behavior. Englewood Cliffs, N.J.: Prentice-Hall.

Bagnardi, M. (2006). Nursing faculty intention to use service learning as pedagogy in higher education. Retrieved from ProQuest Digital Dissertations. (3217559)

Ballone, L. M., \& Czerniak, C. M. (2001). Teachers' Beliefs about Accommodating Students' Learning Styles in Science Classes. Electronic Journal of Science Education, 6(2) 1-44.

Barnes, M., Courtney, M.D., Pratt, J., Walsh, A. M., \& Prom, D. H. (2004). School-based youth health nurses: Roles, responsibilities, challenges and rewards. Public Health Nursing. 21(4), 316-322.

Becker, A.E., Grinspoon, S.K., Klibanski, A., \& Herzog, S.B. (1999). Eating disorders. The New England Journal of Medicine, 340(14), 1091-1098.

Black, S. (2002). Starving in silence. American School Board Journal. 189(3). Retrieved from: http://www.asbj.com/2002/03/0302research.html

Burak, L. J. (1994). Examination and prediction of elementary school teachers' intentions to teach HIV/AIDS education. AIDS Education \& Prevention, 6(4), 310-321.

Burak, L. J. (2002). Predicting elementary school teachers' intentions to teach health education: an application of the theory of planned behavior. American Journal of Health Education. 33(1), 4-9. 
Bureau of Labor Statistics, U.S. Department of Labor, Occupational Outlook Handbook, 2008-2009 Edition, Teachers-Preschool, Kindergarten, Elementary, Middle, and Secondary., retrieved from: http://www.bis.gov/oco/ocos069.htm

Calabrese, R. L., Hummel, C., \& San Martin, T. (2007). Learning to appreciate at-risk students: Challenging the beliefs and attitudes of teachers and administrators. International Journal of Educational Management, 21(4) 275-291.f8f8

Carlton, P. A., \& Deane, F. P. (2000). Impact of attitudes and suicidal ideation on adolescent's intentions to seek professional psychological help. Journal of Adolescence, 23(1), 35-45(11).

Chally, P. S. (1998). An eating disorders prevention program. Journal of Child and Adolescent Psychiatric Nursing. Retrieved from: http: www.findarticles.com/p/articles/mi_qa3892/is_199804/ai_n8800393/print

Charpentier, C. (1994). Barriers to environmental education in Costa Rica State universities: Theory, analysis and recommendations for intervention programs. Retrieved from: http://newfirstsearch.oclc.org/WebZ/FSPage?pagename=record: pagetype $=$ print

Claude-Pierre, P. (1997). The secret language of eating disorders. New York, NY: Random House, Inc.

Cohen, J. (1977). Statistical power analysis for the behavioral sciences ( $2^{\text {nd }}$ ed.). New York, NY: Academee Press.

Cohen, L., Manion, L., Morrison, D., \& Falmer, R. (2000). Research methods in education. London and New York: Routledge Falmer.

Cohen, J., Cohen, P., West, S.G., \& Aiken, L.S. (2002). Applied multiple regressioncorrelation analysis for the behavioral sciences (3rd ed.). Mahwah, N. J.: Lawrence Erlbaum.

Crawley, F. E. (1990). Intentions if science teachers to use investigative teaching methods: A test of the theory of planned behavior. Journal of Research in Science Teaching, 27(7), 685-697.

Crosscope-Happel (1999). Male anorexia: An exploratory study. (Doctoral dissertation, Virginia Polytechnic Institute and State University). Retrieved from http://scholar.lib.vt.edu/theses/available/etd-111599-131446/unrestricted/etd.pdf

Davis, L. E., Ajzen, I., Saunders, J., \& Williams, T. (2002). The decision of African American students to complete high school: An application of the theory of planned behavior. Journal of Educational Psychology, 94(4), 810-819. 
Dee, J. R., Henkin, A. B., \& Pell S. W. (2002). Support for innovation in site based managed schools: Developing a climate for change. Educational Research Quarterly, 27(4), 36-49.

Dixon-Works, D., Nenstiel, R.O., \& Aliabadi, A. (2003). Common eating disorders: A primary for primary care providers. Clinician Reviews. 13(9), 46-52.

Dryfoos, J. G. (1990). Adolescents at risk: Prevalence and prevention. New York, NY: Oxford University Press, Inc.

Field, A. (2005). Discovering statistics using SPSS ( $2^{\text {nd }}$ ed). Thousand Oaks, CA: Sage.

Fishbein, M., \& Ajzen, I. (1975). Strategies of change: Persuasive communication. In belief, attitude, intention and behavior: An introduction to theory and research. 451-562. Reading, MA: Addison-Wesley Publishing.

Griffin, J., \& Harris, M. B. (1996). Coaches' attitudes, knowledge, experiences, and recommendations regarding weight control. The Sport Psychologist, 10, 180-194.

Haney, J.J., Czerniak, C.M., \& Lumpe, A. T. (1996). Teacher beliefs and intentions regarding the implementation of science education reform strands. Journal of Research in Science Teaching, 33(9), 971-993.

Hellings, B., \& Bowles, T. (2007). Understanding and managing eating disorders in the school setting.[ on-line] Austrailian Journal of Guidance and Counseling, 17(1), 60-67. Retrieved from: http://search.informit.com.au/documentSummary;dn000757672844617:res=IELH SS $>$ ISSN: $1037=2911$

Hill, T., \& Lewicki, P. (2006). Statistics methods and applications: A comprehensive reference for science, industry, and data mining. Tulsa: StatSoft

Hoek, H. W. \& van Hoeken, D. (2003). Review of the prevalence and incidence of eating disorders. International Journal of Eating Disorder,34(4) 383-396.

Retrieved from: http://www.ncbi3.interscience.wiley.com/journal/106557769/abstract.

Housman, J. (2006). Understanding female collegiate athletes' intentions to consume sports supplements: An application of the theory of planned behavior. (Doctoral Dissertation, Texas A \& M University). Retrieved from http://repository.tamu.edu/bitstream/handle/1969.1/5808/etd-tamu-2006A-HEEDHousman.pdf? sequence $=1$

Judge, J.E. (2001). A survey of school psychologists' knowledge of an intervention with students with anorexia and bulimia nervosa. 62(11A). Retrieved from: http://2082/WebZ/FSFETCH/fetchtype=fullrecord:sessionid=sp07sw02-58451dwvh57 
Kates, K. J., Rohwer, J., \& Londre, K. (2002). Evaluation of an upper elementary school program to prevent body image, eating, and weight concerns. Journal of School Health, 72(5), 199-205.

Kerlinger, F.N., \& Lee, H. B.(2000). Foundations of behavioral research. $\left(4^{\text {th }}\right.$ ed.). United States, Wadsworth: Thomson Learning, Inc.

Kohn, M., \& Golden, N. H. (2001). Eating disorders in children and adolescents: Epidemiology, diagnosis and treatment. Paediatr Drugs, 3(2), 91-99.

laGrange, D., \& Loeb, K.L. (2007). Early identification and treatment of: Prodrome to syndrome Early Intervention in Psychiatry, 1, 27-39.

Layton, E.A. (2003). Secondary prevention of eating disorders: The teachers' perspective. 1-77. Retrieved from: https://wwwlib.umi.com/dissertations/preview pageMQ78095/1

Levitt, D.H. (2001). Anorexia nervosa: Treatment in the family context. The Family Journal: Counseling and Therapy for Couples and Families, 9(2), 159-163.

Lord, H. G. (1973). Expost Facto Studies as a Research Method. Special Report. No. 7320. US Department of Health, Education \& Welfare National Institute of Education.

Lumpe, A. T., Haney, J. J., \& Czerniak, C. M. (1998). Science teacher beliefs and intentions regarding the use of cooperative learning. School Science and Mathematics, 98(3), 123-136.

Manley, R., Rickson, H., \& Standeven, B. (2000). Children and adolescents with eating disorders: Strategies for teachers and school counselors. Intervention in School and Clinic, 35(4), 228-231.

Martin, J. J., Kulinna, P. H., Eklund, R., \& Reed, B. (2001). Determinants of teachers' intentions to teach physically active physical education classes. Journal of Teaching in Physical Education, 20, 129-143.

McCabe, M.P., \& Ricciardelli, L.A. (2004). Body image dissatisfaction among males across the lifespan: A review of past literature. Journal of Psychosomatic Research, 56(6), 675-685. Retrieved from: doi:10.1016/s0022-3999(03)00129-6

McEwen, M. (2002). Community-based nursing: An introduction. St. Louis, Mo: Saunders.

McKenna, H. P. (1997). Nursing models and theories. London: Routledge, 144-146. 
McMillan, J.H., \& Schumacher, S. (2001) Research in education: A conceptual introduction ( $5^{\text {th }}$ ed.). New York, NY: Addison Wesley Longman, Inc.

McNeil, K., Newman, I., \& Kelly, F.J. (1996). Testing research hypotheses with the general linear model. Carbondale: Southern Illinois University Press.

Mertler, C. A., \& Vannatta, R. A.. (2002). Advanced and multivariate statistical methods: Practical applications and interpretation ( $2^{\text {nd }}$ ed.). Los Angeles, CA: Pyrczak.

Munro, B. H. (2005). Statistical methods for health care research. Philadelphia, PA: Lippincott Williams \& Wilkins.

Murray, T. (2003). Wait not, want not: Factors contributing to the development of anorexia nervosa and bulimia nervosa. The Family Journal: Counseling and Therapy for Couples and Families, 11(3), 276-280.

Myers-Clack, S., \& Christopher, S. (2000). Examining the effectiveness of a health course in influencing pre-service teachers' knowledge of and attitudes toward health in schools. Retrieved from: http//apha.confex.com/apha/128am/techprogram/paper_5535.htm

Napoli, M. (2000). Mindfulness Training for teachers: A pilot program. Retrieved from: http:216.239.41.104/search?q=cache:oWIK8sp8eHgJ:home.uchicago. edu/ wiles/articles/napoli.pdf

Natenshon, A. (1996). Self-esteem and healthy eating. What does one thing have to do with the other? Everything. In ED Referral.com. Retrieved from: http:www.edreferral.com/children_\&_ed.htm

Neumark-Sztainer, D., Story, M., \& Coller, T. (1999). Perceptions of secondary school staff toward the implementation of school-based activities to prevent weightrelated disorders: A needs assessment. American Journal of Health Promotion, $13,153-156$.

Newman, I., \& Newman, C. (1994) Conceptual statistics for beginners. Washington, D.C.: University Press of America.

Nunnally, J. C., \& Bernstein, I. H. (1994). Psychometric theory (3 ${ }^{\text {rd }}$ ed.). NY: McGrawHill.

O’Dea, J. A., \& Abraham, S. (2001). Knowledge, beliefs, attitudes, and behaviors related to weight control, eating disorders, and body image in Australian trainee home economics and physical education teachers. Journal of Nutrition Education, 33(6), 332-341. 
Paxton, S.J. (1999). Peer relations, body image, and disordered eating in adolescent girls: Implications for prevention. In. N. Piran, M.P. Levine, \& C. Steiner-Adair, Preventing eating disorders: A handbook of interventions and special challenges (pp. 134-147). Philadelphia, PA: Brunner/Mazel.

Polit, D.F., \& Beck, C.T. (2004). Nursing research: Principles and methods $\left(7^{\text {th }}\right.$ ed.). Philadelphia, PA: Lippincott Williams \& Wilkins.

Pedhazur, E. J. (1981). Multiple regression in behavioral research: Explanation and prediction. Fort Worth, TX: Holt Rinehart \&Winston, Inc.

Pender, N. J., Murdaugh, C. L., \& Parsons, M. A. (2006). Health promotion in nursing practice $\left(5^{\text {th }}\right.$ ed.). New Jersey, NJ: Pearson Prentice Hall.

Peterson, S J., \& Bredow, T. S. (2004). Middle range theories: Application to nursing research. Philadelphia: Lippincott Williams \& Wilkins.

Phelps, L., Sapia, J., Nathenshon, D., \& Nelson, L. (2000). An empirically supported eating disorder prevention program. Psychology in the Schools, 37(5), 443-452.

Piran, N. (2004a). Teachers: On "being" (rather than "doing") prevention. Eating Disorders, 12, 1-9.

Piran, N. (2004b). Prevention of eating disorders-A dilemma. National Institute of Nutrition. Retrieved from:

http://www.nin.ca/public_html/Publications/Rapport/rapp1_93_p.html

Pryor, T., \& Wiederman, M.W. (1998). Personality features and expressed concerns of adolescents with eating disorders. Adolescence, 33(130), 291-300.

Ransley, J. K. (1999). Eating disorders and adolescents: What are the issues for secondary schools? Health Education, 1, 35-42.

Rayman, J., \& Piran, N. (2002). Eating disorder prevention practices among middle school teachers. Unpublished manuscript.

Rees, L., \& Clark-Stone, S. (2006). Can collaboration between education and health professionals improve the identification and referral of young people with eating disorders in schools? A pilot study. Journal of Adolescence, 29(1), 137-151.

Rhodes, R. E., \& Courneya, K. S. (2003). Modeling the theory of planned behaviour and past behaviour. Psychology, Health \& Medicine, 8(1), 57-68.

Romeo, F.F. (1996). Educators and the onset of anorexia nervosa in young girls. Education, 117, 55-57. 
Roeser, R. W., \& Midgley, C. (1997). Teachers' views of issues involving students' mental health. The Elementary School Journal, 98(2) 115-132.

Sands, R., Tricker, J. Sherman, C., Armatas, C., \& Maschette, W. (1997). Disordered eating patterns, body image, self-esteem, and physical activity in preadolescent school children. International Journal of Eating Disorders, 21(2), 159-166.

Shahid, B., (2003). A study of school principals and the promotion of nutritional health in middle grade schools. Education, 123(3), 552.

Skemp-Arlt, K. M., Rees, K. S., Mikat, R. P. \& Seebach, E.E. (2006). Body image dissatisfaction among third, fourth, and fifth grade children. Californian Journal of Health Promotion, 4(3), 58-67. Retrieved from http://www.csuch10.edu/cjhp/4/3/58-67-skemp-arlt.pdf

Smolak, L., Harris, B., Levine, M. P., \& Shisslak, C. M. (2001). Teachers: The forgotten influence on the success of prevention programs. Eating Disorders: The Journal of Treatment and Prevention, 9, 261-265.

St. Leger, L., \& Nutbeam, D. (2000). A model for mapping linkages between health and education agencies to improve school health.The Journal of School Health, 70(2), 45-50.

Stanhope, M., \& Lancaster, J. (2008). Public health nursing: Population-centered health Care in the community, $\left(7^{\text {th }}\right.$ ed.). Philadelphia, PA: Mosby, Inc.

Stockburger, D.W. (1998). Multivariate statistics: Concepts, models, and applications. Retrieved from: http://www.psychstat.missouristate.edu/multibook/mlt00.htm

Tabachnick, B.G., \& Fidell, L. S. (2001). Using multivariate statistics. Boston, MA: Allyn \& Bacon.

Videbeck, S.L. (2008). Psychiatric-mental health nursing. Wolters Kluwer Health. Lippincott Williams \& Wilkins.

Vogt, W.P. (2005). Dictionary of statistics and methodology: A nontechnical guide for the social sciences, $\left(3^{\text {rd }}\right.$ ed.). Thousand Oaks, CA: Sage Publications.

Webb, A. (1994). The starvation demons. Maclean's, 2 May:50.

Wiederman, M. W., \& Pryor, T. L. (2000). Body dissatisfaction, bulimia, and depression among women: The mediating role of drive for thinness. International Journal Eating Disorder, 27(1), 90-95. 
Wisenhunt, B.L. (2002). Prevention of eating disorders in athletes: An intervention for coaches. (Doctoral dissertation).Retrieved from http://etd.lsu.edu/docs/available/etd 0615102-024648/unrestricted/Whisenhunt -dos.pdf

Yager, Z., \& O'Dea, J. A. (2005). The role of teachers and other educators in the prevention of eating disorders and child obesity: What are the issues? Eating Disorders, 13, 261-278.

Zint, M. (2002). Comparing three attitude-behavior theories for predicting science teachers' intentions. Journal of Research in Science Teaching, 39(9), 819-844. 


\section{APPENDICES}


Appendix A - Cover Letter for the Participants 


\section{Dear Participant,}

My name is Diann Carr, and I am a doctoral candidate from Florida International University College of Education, and a nursing professor at another university in South Florida. I am working on my dissertation entitled "Middle School Teachers Intentions to Refer Eating Disorder Students for Professional Counseling" and would greatly appreciate your participation.

I am asking middle school teachers to answer a few questions on a questionnaire to assist me in my dissertation study. If you decide to participate you will be asked to complete a demographic survey and questionnaire. Your consent to be a research participant is strictly voluntary, and you may decline to participate at any time. There will be no adverse effects if you decide not to participate. Anonymity will be ensured by not requiring a name on the questionnaire. Information provided by each participant will be held under strict confidence.

The attached questionnaire contains questions written specifically for middle school teachers about referring eating disorder students to professional counseling. Completing the questionnaire should take approximately 20 minutes. The only indicator on the survey will be one identifying your institution. All the information provided by each participant will be held under strict confidence. Any published results of this study will be reported as an aggregate and no personal identifiers will be used. Your questionnaire will be held in strict confidence.

If you have any question or any comments, please feel free to contact me through my email at dcarr@mail.barry.edu, or 954-816-0097. My dissertation Chairperson is Dr. J. Wynne, PhD, Faculty Member of the College of Education at Florida International University, Miami, Florida. Dr. J. Wynne’s email address is wynnej@fiu.edu

Thank you for your participation and support.

Sincerely,

Diann Carr 
Appendix B - Demographic Survey and Questionnaire 


\section{Questionnaire}

Part I

The following items seek to understand your attitude regarding referring students for counseling that you suspect of having an eating disorder problem. For the purposes of this questionnaire, eating disorders are defined as either anorexia nervosa (anorexia) or bulimia nervosa (bulimia).
a. There are no correct or incorrect responses
b. Be sure to answer all items---do not omit any questions
c. Never circle more than one number on a single question

\section{Part II}

Please circle the number that best describes the way you feel about referring students for counseling that you suspect of having an eating disorder problem. Rate your attitude on a 7-point scale wherein 1 indicates an extremely low attitude and 7 indicates an extremely high attitude. Mark your responses in the scale provided below.

$\begin{array}{ccccccc}1 & 2 & 3 & 4 & 5 & 6 & 7 \\ \text { Extremely } & \text { Quite } & \text { Slightly } & \text { Neither Low } & \text { Slightly } & \text { Quite } & \text { Extremely } \\ \text { Low } & \text { Low } & \text { Low } & \text { Nor High } & \text { High } & \text { High } & \text { High }\end{array}$

For me, referring a student that I suspect of having an eating disorder for counseling is:

$\begin{array}{lllllllll}\text { 1. Useless } & 1 & 2 & 3 & 4 & 5 & 6 & 7 & \text { Useful } \\ \text { 2. Inappropriate } & 1 & 2 & 3 & 4 & 5 & 6 & 7 & \text { Appropriate } \\ \text { 3. Time consuming } & 1 & 2 & 3 & 4 & 5 & 6 & 7 & \text { Time saving } \\ \text { 4. Unsuccessful } & 1 & 2 & 3 & 4 & 5 & 6 & 7 & \text { Successful } \\ \text { 5. Impractical } & 1 & 2 & 3 & 4 & 5 & 6 & 7 & \text { Practical } \\ \text { 6. Complex } & 1 & 2 & 3 & 4 & 5 & 6 & 7 & \text { Simple } \\ \text { 7. Difficult } & 1 & 2 & 3 & 4 & 5 & 6 & 7 & \text { Easy } \\ \text { 8. Unsafe } & 1 & 2 & 3 & 4 & 5 & 6 & 7 & \text { Safe }\end{array}$

9. By my referring a student suspected of having an eating disorder it would increase student learning.
Unlikely 1
2
3
4
5
6
7
Likely 
10. By my referring a student suspected of having an eating disorder it would take time away from covering important educational content.
Unlikely
1
2
3
4
56
7 Likely

11. Referring a student that I suspect of having an eating disorder is part of my teaching responsibility.

$\begin{array}{lllllllll}\text { Completely False } & 1 & 2 & 3 & 4 & 5 & 6 & 7 & \text { Completely True }\end{array}$

The decision to refer a student for counseling that you suspect of having an eating disorder problem may be influenced by a number of people that are important in your life. The following statements have been constructed based on feedback from other faculty members asked to identify those groups of people they viewed as being important in their decisions.

Please respond to the following sentences based on your own perceptions.

12. Most people who are important to me think that I (indicate response below) refer, for counseling, students suspected of having an eating disorder.

$\begin{array}{llllllll}\text { Should Not } & 1 & 2 & 3 & 4 & 5 & 6 & 7 \text { Should }\end{array}$

13. Other middle school teachers who are important to me think that I (indicate response below) refer, for counseling, students suspected of having an eating disorder.

$\begin{array}{llllllll}\text { Should Not } 1 & 2 & 3 & 4 & 5 & 6 & 7 & \text { Should }\end{array}$

14. My administrators think that I (indicate response below) refer, for counseling, students suspected of having an eating disorder.

$\begin{array}{lllllllll}\text { Should Not } & 1 & 2 & 3 & 4 & 5 & 6 & 7 & \text { Should }\end{array}$

15. The guidance counselor thinks that I (indicate response below) refer, for counseling, students suspected of having an eating disorder.

$\begin{array}{lllllllll}\text { Should Not } & 1 & 2 & 3 & 4 & 5 & 6 & 7 & \text { Should }\end{array}$

16. The people in my life whose opinion I value would (indicate response below) of my referring students suspected of having an eating disorder for counseling.

$\begin{array}{lllllllll}\text { Strongly Disapprove } & 1 & 2 & 3 & 4 & 5 & 6 & 7 & \text { Strongly Approve }\end{array}$

17. It is expected of me to refer, for counseling, students suspected of having an eating disorder.

$\begin{array}{lllllllll}\text { Strongly Disagree } & 1 & 2 & 3 & 4 & 5 & 6 & 7 & \text { Strongly Agree }\end{array}$ 
18. It is a professional obligation for me to refer, for counseling, students suspected of having an eating disorder.

$\begin{array}{lllllllll}\text { Strongly Disagree } & 1 & 2 & 3 & 4 & 5 & 6 & 7 & \text { Strongly Agree }\end{array}$

19. Most people who are important to me would expect me to refer, for counseling, students I suspect of having an eating disorder.

$\begin{array}{llllllllll}\text { Completely False } & 1 & 2 & 3 & 4 & 5 & 6 & 7 & \text { Completely True }\end{array}$

20. My administrators influence my decision to refer, for counseling, students I suspect of having an eating disorder.

$\begin{array}{lllllllll}\text { Strongly Disagree } & 1 & 2 & 3 & 4 & 5 & 6 & 7 & \text { Strongly Agree }\end{array}$

The decision to refer a student for counseling that you suspect of having an eating disorder problem may be influenced by your perception of your ability, skills, and/or knowledge to make such a referral.

Please respond to the following statements based on your own perception of your ability, skill and/or knowledge necessary to refer students to counseling that you suspect of having an eating disorder problem.

21. For me referring students suspected of having an eating disorder to appropriate counseling would be

$\begin{array}{llllllll}\text { Impossible } 1 & 2 & 3 & 4 & 5 & 6 & 7 & \text { Possible }\end{array}$

22. If I wanted to, I could refer students suspected of having an eating disorder for counseling.

$\begin{array}{lllllllll}\text { Definitely False } & 1 & 2 & 3 & 4 & 5 & 6 & 7 & \text { Definitely True }\end{array}$

23. How much control do you believe that you have over referring students suspected of having an eating disorder for counseling?

$\begin{array}{lllllllll}\text { No Control } 1 & 2 & 3 & 4 & 5 & 6 & 7 & \text { Complete Control }\end{array}$

24. It is up to me if I refer students suspected of having an eating disorder for counseling.

$\begin{array}{lllllllll}\text { Strongly Disagree } & 1 & 2 & 3 & 4 & 5 & 6 & 7 & \text { Strongly Agree }\end{array}$

25. I am aware of the guidelines and procedures to be followed to refer students suspected of having an eating disorder for counseling.

$\begin{array}{lllllllll}\text { Strongly Disagree } & 1 & 2 & 3 & 4 & 5 & 6 & 7 & \text { Strongly Agree }\end{array}$ 
26. School policies regarding referrals for counseling make it difficult for me to refer students suspected of having an eating disorder.

$\begin{array}{lllllllll}\text { Strongly Disagree } & 1 & 2 & 3 & 4 & 5 & 6 & 7 & \text { Strongly Agree }\end{array}$

27. My teaching responsibilities make it difficult for me to refer students suspected of having an eating disorder for counseling.

$\begin{array}{lllllllll}\text { Strongly Disagree } & 1 & 2 & 3 & 4 & 5 & 6 & 7 & \text { Strongly Agree }\end{array}$

28. I have the knowledge necessary to detect an eating disorder and make a referral for counseling for such a disorder.

$\begin{array}{lllllllll}\text { Strongly Disagree } & 1 & 2 & 3 & 4 & 5 & 6 & 7 & \text { Strongly Agree }\end{array}$

29. There is adequate administrative support at my school for me to refer, for counseling, students suspected of having an eating disorder.

$\begin{array}{lllllllll}\text { Strongly Disagree } & 1 & 2 & 3 & 4 & 5 & 6 & 7 & \text { Strongly Agree }\end{array}$

30. There is adequate teacher support at my school for me to refer students, for counseling, suspected of having an eating disorder.

$\begin{array}{lllllllll}\text { Strongly Disagree } & 1 & 2 & 3 & 4 & 5 & 6 & 7 & \text { Strongly Agree }\end{array}$

31. There are adequate procedures in place at my school to insure confidentiality when referring, for counseling, a student suspected of having an eating disorder.

$\begin{array}{lllllllll}\text { Strongly Disagree } & 1 & 2 & 3 & 4 & 5 & 6 & 7 & \text { Strongly Agree }\end{array}$

32. In your role as a middle school teacher, have you ever suspected a student of having an eating disorder?

No ___ (If no, please skip to question 34 which addresses your future intentions regarding referring students that you suspect of having an eating disorder for counseling).

Yes ___ (If yes, please continue to the next question).

Your perceptions may be associated with your future and past actions regarding referring students to counseling that you suspected of having an eating disorder problem. Now, reflect back to any student that you have previously suspected of having an eating disorder and respond based on your actions in the past.

33. Have you ever referred a student that you suspected of having an eating disorder for counseling related to this problem? 
Yes ___ (If yes, please identify factors and explain the factors below that facilitated your referring the student for counseling for the eating disorder).

No ___ (If no, please identify factors and explain the factors below that inhibited you from referring the student for counseling for the eating disorder).

The following questions are related to your future intentions regarding referring students to counseling that you suspect of having an eating disorder problem.

34. I aim to refer students suspected of having an eating disorder.
Unlikely
2
3
4
5
6
7
Likely

35. I will try to refer students suspected of having an eating disorder.
Unlikely
2
3
4
5
6
7
Likely

36. I intend to refer students suspected of having an eating disorder.

$\begin{array}{lllllllll}\text { Unlikely } & 1 & 2 & 3 & 4 & 5 & 6 & 7 & \text { Likely }\end{array}$




\section{Part III}

Gender:

1. Male

2. Female

Ethnicity:

1. White

2. African-American

3. Hispanic

4. Asian

5. African Caribbean

6. Other

The highest degree you have achieved:

1. BA

2. $\mathrm{BS}$

3. M.Ed.

4. MAT

5. Ed.D.

6. Ph.D.

7. Other

Age:

20-29

30-39

40-49

50-59

60 or more

THANK YOU VERY MUCH FOR YOUR PARTICIPATION!

$\underline{\mathrm{dc} / 2010}$ 
Appendix C - Flyer 


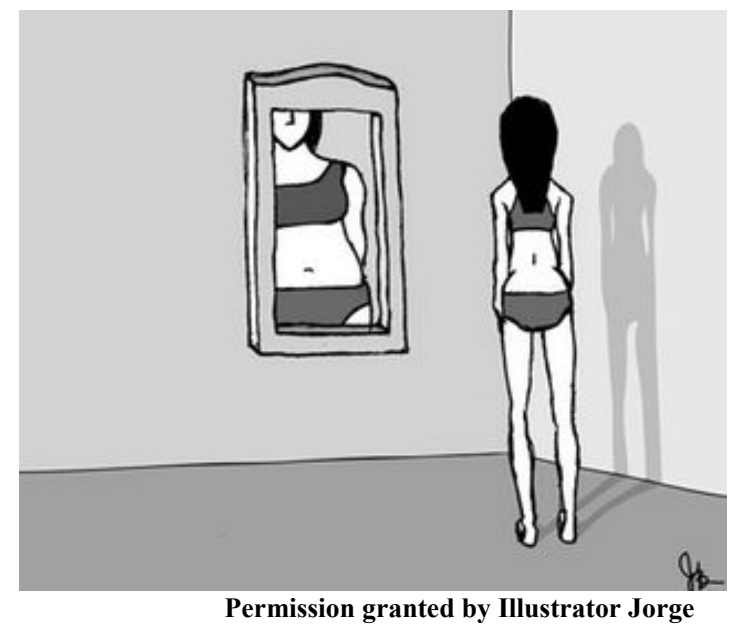

\section{Seeking your participation for my Doctoral Research Study}

The topic is:

Middle School Teachers Intention to Refer Students Suspected of Anorexia Nervosa and Bulimia Nervosa to Professional

Counseling

In one week I will be providing a questionnaire to the teachers in your school. Your participation is voluntary and anonymous. I would appreciate it if you could help me by filling out the questions.

The questionnaires will be placed in your individual mailboxes. After one week I will collect the completed questionnaires from a specified contact person in your school. The name of the contact person will be written on the questionnaire envelope. There will be a designated space for the collection box for the completed questionnaires and this information will be found on the questionnaire envelope. If you have any questions the contact person can reach me, Diann Carr, and I will be glad to get back with you.

\section{THANK YOU SO MUCH !!!!!!!!!!!!!!}

This research is being conducted as partial fulfillment for my doctoral program in education at Florida International University. Thanks again, Diann Carr 
Appendix D - Reminder Flyer 


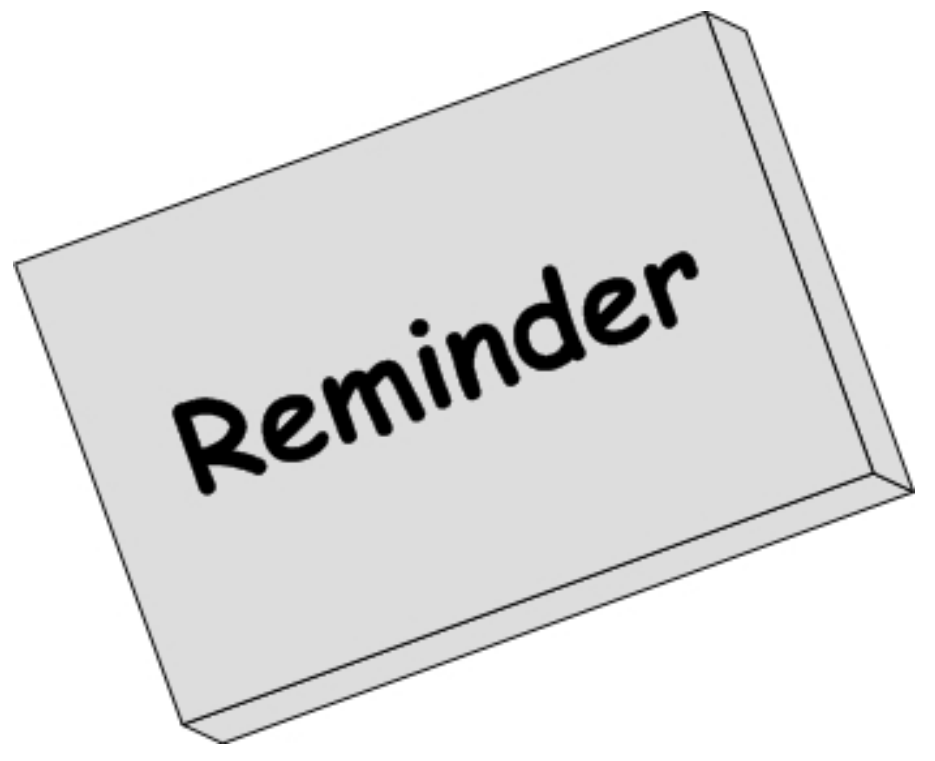

This is just a reminder to fill out the questionnaire for Diann Carr, doctoral student from Florida International University.

I will be collecting the questionnaires in 3 days. Date

Thank you so much for your participation and your help with my study regarding:

MIDDLE SCHOOL TEACHERS' INTENTIONS TO REFER EATING DISORDER STUDENTS FOR PROFESSIONAL COUNSELING

Thanks again, Diann Carr 
VITA

EDUCATION

DIANN CARR

\begin{tabular}{|c|c|}
\hline $1959-1962$ & $\begin{array}{l}\text { RN, Nursing } \\
\text { St. Joseph's School of Nursing } \\
\text { Pittsburgh, Pennsylvania }\end{array}$ \\
\hline $1966-1971$ & $\begin{array}{l}\text { BSN, Nursing } \\
\text { Duquesne University } \\
\text { Pittsburgh, Pennsylvania }\end{array}$ \\
\hline 1990-1993 & $\begin{array}{l}\text { MSN, Nursing Education } \\
\text { Barry University } \\
\text { Miami Shores, Florida }\end{array}$ \\
\hline 1996-1997 & $\begin{array}{l}\text { ARNP, Mental Health Nurse Practitioner } \\
\text { Florida International University } \\
\text { Miami, Florida }\end{array}$ \\
\hline 2011-1999 & $\begin{array}{l}\text { Doctoral Candidate } \\
\text { Florida International University } \\
\text { Miami, Florida }\end{array}$ \\
\hline 2011 & $\begin{array}{l}\text { Ed.D., Doctor of Education } \\
\text { Florida International University } \\
\text { Miami, Florida }\end{array}$ \\
\hline $\begin{array}{l}\text { EMPLOYMENT } \\
\text { Psychiatric Staff Nurse } \\
1962-1963\end{array}$ & $\begin{array}{l}\text { St. Francis Hospital } \\
\text { Pittsburgh, Pennsylvania }\end{array}$ \\
\hline $\begin{array}{l}\text { Nursing Instructor } \\
1963-1967\end{array}$ & $\begin{array}{l}\text { St. Francis Hospital School of Nursing } \\
\text { Pittsburgh, Pennsylvania }\end{array}$ \\
\hline $\begin{array}{l}\text { Psychiatric Nurse } \\
1985-1989\end{array}$ & $\begin{array}{l}\text { Home Health of the U.S. } \\
\text { Hallandale, Florida }\end{array}$ \\
\hline $\begin{array}{l}\text { Psychiatric Nurse } \\
1985-1989\end{array}$ & $\begin{array}{l}\text { Visiting Nurse Association } \\
\text { Home Health } \\
\text { Ft. Lauderdale, Florida }\end{array}$ \\
\hline $\begin{array}{l}\text { Nursing Instructor } \\
1982-1994\end{array}$ & $\begin{array}{l}\text { Broward Community College } \\
\text { Ft. Lauderdale, Florida }\end{array}$ \\
\hline
\end{tabular}




\section{Adjunct Nursing Faculty \\ Instructor \\ 1992-1994}

Adjunct Faculty Adult Education

Instructor

1992-1996

\section{Assistant Professor \\ 1994-Present}

\author{
Barry University \\ Miami Shores, Florida
}

Broward Community College

Ft. Lauderdale, Florida

Barry University

Miami Shores, Florida

\section{SCHOLARSHIP}

Podium presentation:

Carr, D. ( 2004). Is the School Environment a Contributing Factor in Triggering Episodic Bingeing and Purging Behaviors: The Lived Experience of Two Self-Reported Bulimic RN Students That Had Attended an Undergraduate Nursing Program to Receive a BSN Degree accepted for a presentation at the 15 th International Nursing Research Congress, Dublin, Ireland.

Carr, D. (2005). "Secrets That Need To Be Told: The Lived Experience of Two Registered Nurses Attending a Baccalaureate Nursing Program. Podium presentation presented at16th International Nursing Research Congress, Hawaii.

Poster presentation:

Carr, D. ( 2011). Simulation: Interactive Teaching Strategy for Psychiatric Nursing Students. Poster session presented at the First Annual Florida Nurses Association South Region Symposium at Davie, Florida.

Carr, D. ( 2011). Simulation: Interactive Teaching Strategy for Psychiatric Nursing Students. Poster session presented at the 2011 Sigma Theta Tau International-Lambda Chi Chapter at Barry University, Division of Nursing, at Miami Shores, Florida.

Carr, D. (2008). Journaling Benefits Faculty and Students. Poster accepted at the 2008 Gulf South Summit Belmont University in Nashville, Tennessee.

Carr, D. (2008). Opening the Door to Health in the Community through Service Learning. Poster accepted at the 2008 Gulf South Summit Belmont University in Nashville, Tennessee.

Carr, D. (2006). Nursing Students Reaching Out to the Underserved in Miami and Broward Counties. Poster accepted at the $17^{\text {th }}$ International Nursing Research Congress Fourth International Evidence-Based Nursing Pre-conferences Montreal, Canada.

Carr, D. (2005). Nursing Students Reaching Out Through Community Partnerships to Help Underserved Populations. Poster session presented at Gulf South Summit Conference, Melbourne, Florida. 